= KAPL-3119

二 AEC Research and

- Development Report

\title{
Ductile-to-Brittle Transition of
}

Niobium-Vanadium Alloys

\author{
as \\ Affected by Notches, \\ Strain Rate, Nitrogen, \\ and \\ Oxygen
}

RETEASED FOR ANYUTCEMTNT

IN NUCTEAR SCIENCE ABSIRACIS

\author{
C.D. Calhoun \\ April 1965
}

Operated for the

United States Atomic

Energy Commission by

GENERAL ELECTRIC 


\section{DISCLAIMER}

This report was prepared as an account of work sponsored by an agency of the United States Government. Neither the United States Government nor any agency Thereof, nor any of their employees, makes any warranty, express or implied, or assumes any legal liability or responsibility for the accuracy, completeness, or usefulness of any information, apparatus, product, or process disclosed, or represents that its use would not infringe privately owned rights. Reference herein to any specific commercial product, process, or service by trade name, trademark, manufacturer, or otherwise does not necessarily constitute or imply its endorsement, recommendation, or favoring by the United States Government or any agency thereof. The views and opinions of authors expressed herein do not necessarily state or reflect those of the United States Government or any agency thereof. 


\section{DISCLAIMER}

Portions of this document may be illegible in electronic image products. Images are produced from the best available original document. 
KAPL-3119

UC-25, Metals.; Ceramics, and Materials

RELEASED FOR ANIC'CTENENT

IN NUCLEAR SCIENCE: ABSTRACTS

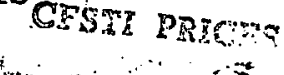

i........ $\because 3$

H: $\rightarrow$

H. C: $\$ 2.00 ; \mathrm{MN}=50$

\title{
DUCTILE-TO-BRITTLE TRANSITION OF NIOBIUM-VANADIUM ALCOYS AS AFFECTED BY NOTCHES, STRAIN RATE, NITROGEN, AND OXYGEN
}

C. D. Calhoun

April 1965

\section{LEGAL NOTICE} This report was prepared as an account of Government sponsored work. Nelther

Sultes, nor the Commission, nor any persos acting on implied, with respect to the accuA. Makes any warranty or representation, expressed or in in this report, or that the use racy, completeness, or usefulsess of the informaton coslosed in this report may nut infringe of any information, apparatus

privately owned rights; or B. Assumes any liablities with respect to the use of, or for din thases report.

B. Assumes any linatus, method, or process disclosed in this report. se of any information, appers "pen acting on behalf of the Commission" includes any emAs used in the above, "permisan, or employee of such contractor, to the extent that ployee or contractor of the Cor ex exployee of such contractor prepares, such employee or contractor of the Cony information pursuant to his employment or contract disseminates, or provldes access to, any with such contractor.

with the Commission, or his employment with such :
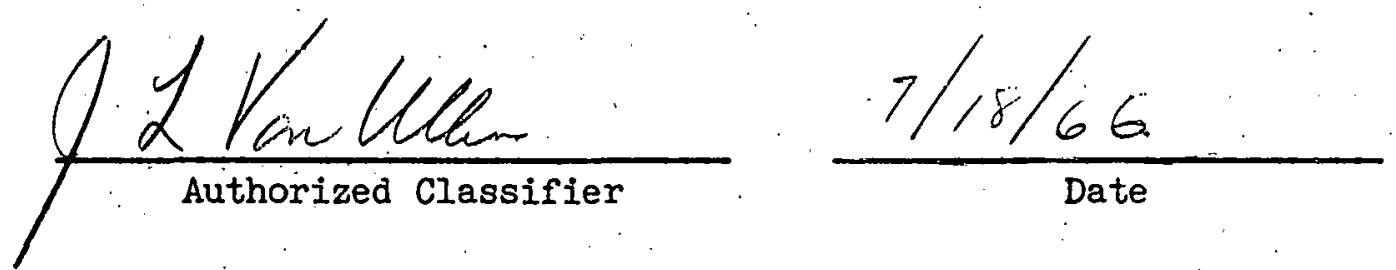

\author{
General Electric Company \\ KNOLIS ATOMIC POWER IAABORATORY \\ Schenectady; New York \\ Operated for the \\ United States Atomic Energy Commission \\ Contract No. W-31-109 Eng-52
}


This report was prepared as an account of Governmentsponsored work. Nelther the United States, nor the Comission, nor any person acting on behalf of the Comission:

A. Makes any warranty or representation, expressed or implied, with respect to the accuracy, completeness, or usefulness of the information contained in this report, or that the use of any information, apparatus, method, or process disclosed in this report may not infringe privately owned rights; or

B. Assumes any liabilities with respect to the use of, or for damages resulting from the use of any information, apparatus, method, or process disclnsed in this report.

As used in the above, "person acting on behalf of the Commission" includes any employee or contractor of the Commission, or employee of such contractor, to the extent that such employre or cuntractor of the commission, or eliployee of such contractor prepares, disseminates, or provides access to, any information pursuant to his employment or contract with the Commission, or his employment with such contractor.

Printed in USA. Price $\$ 3.00$. Available from the Clearinghouse for Federal Scientific and Technical Information, National Bureau of Standards, U. S. Department of Commerce, Springfield, Virginia. 


\title{
Distribution
}

\author{
KAPL-3179 \\ UC-25, Metals, Ceramics, \\ and Materials \\ (Nonstandàrd)
}

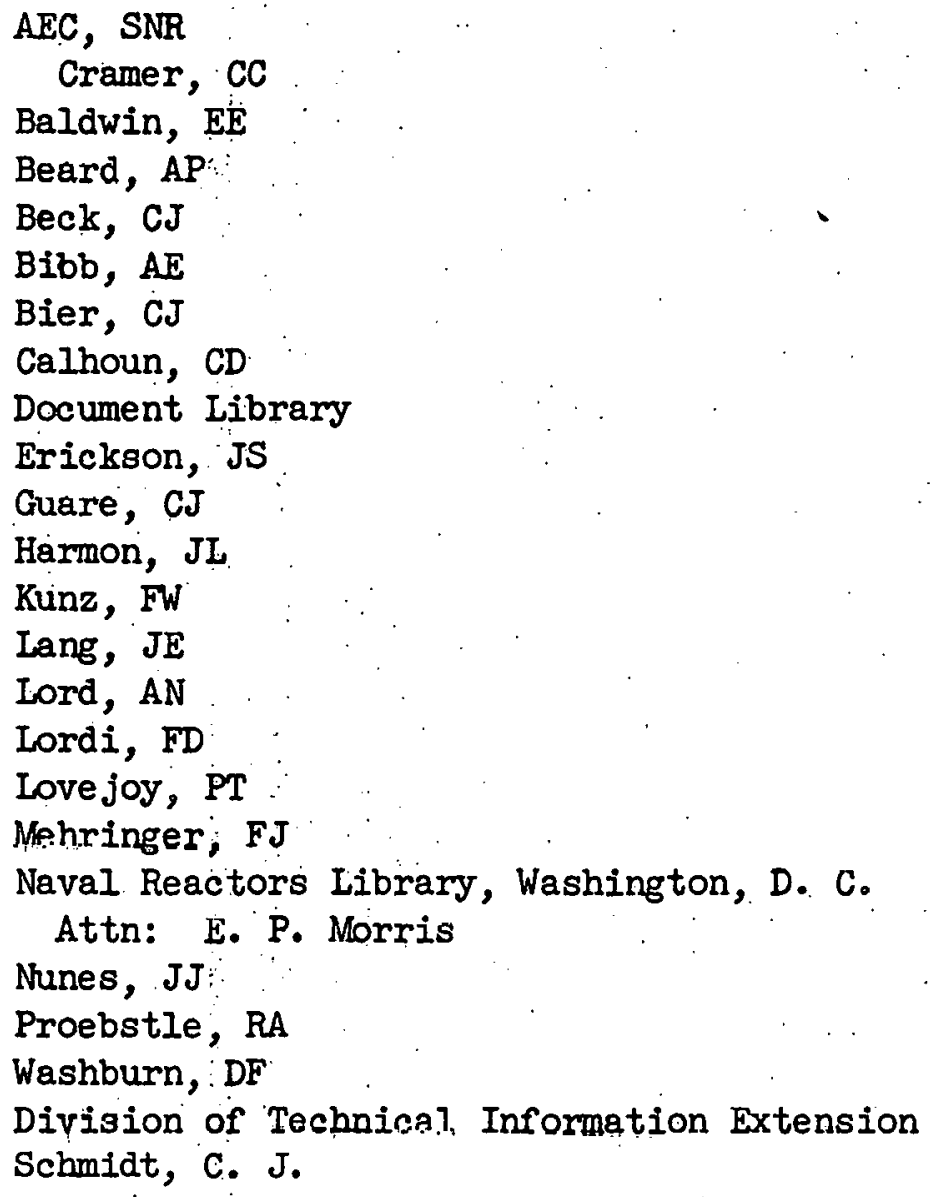


THIS PAGE

\section{WAS INTENTIONALLY LEFT BLANK}


CONTENTS

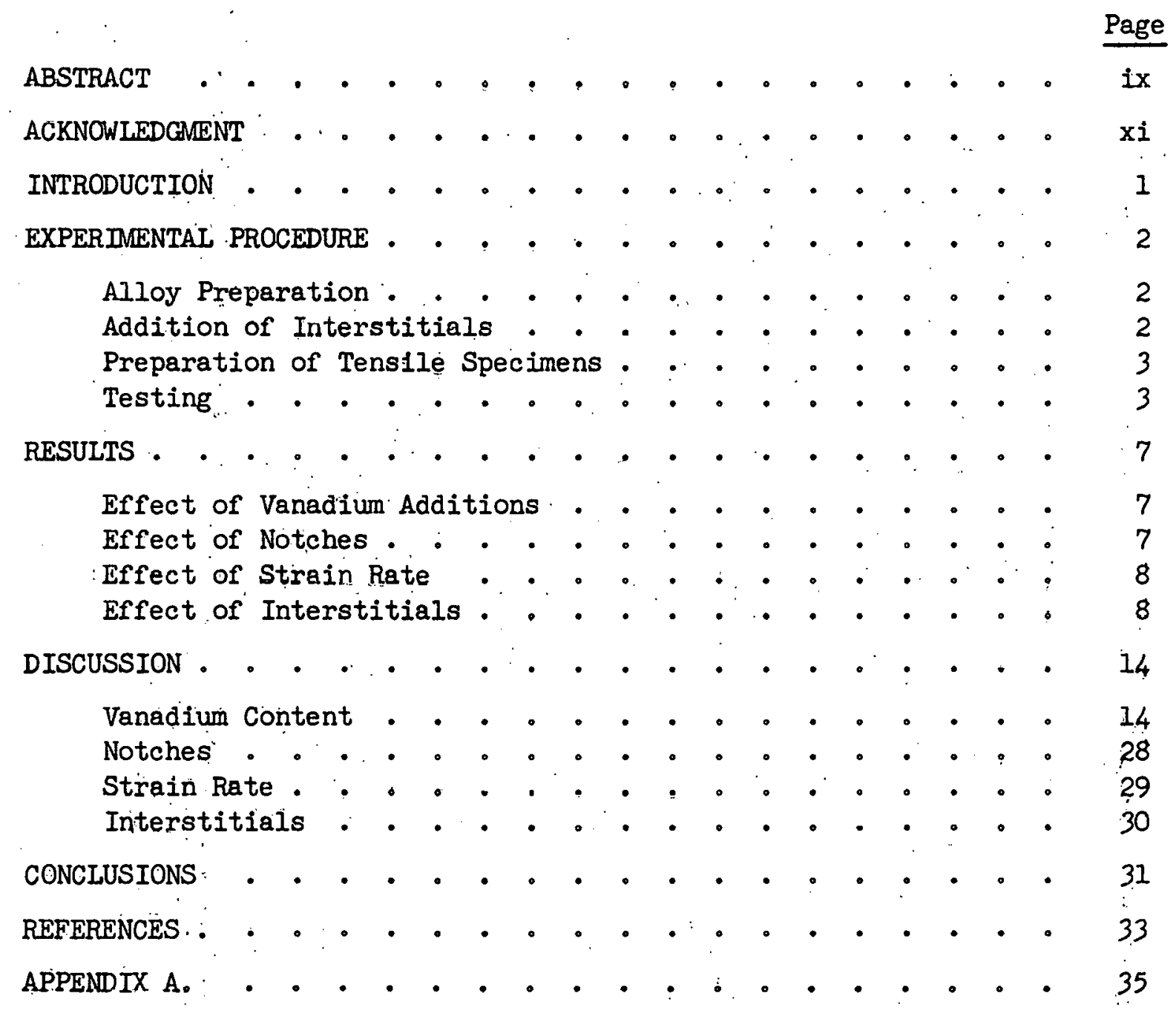


THIS PAGE

\section{WAS INTENTIONALLY \\ LEFT BLANK}




\section{ILLUSTRATIONS}

No

Title

Page

1 Schematic Drawing of Tensile Specimens (KS-59986, Unclassified)

2 Microstructure of Niobium-Vanadium after Recrystallization Anneal of $1 \mathrm{hr}$ at $1200 \mathrm{C}$ (KS-59987, Unclassified) . . . . 5

3 Representative Microstructure of Niobium-Vanadium Alloys after Homogenization Heat-Treatment of 17 Days at $1200 \mathrm{C}$ (KS-59988, Unclassified

4 Variation of Plastic Deformation as a Function of Temperature for Niobium-6 wt \% Vanadium (KS-59989, Unclassified) .. .

5 Microstructure of Niobium-Vanadium Tensile Specimens (KS-59990, Unclassified)

6 Effect of Vanadium on the Ductile-to-Brittle Transition Temperature of Niobium-Vanadium Alloys (KS-59991, Unclassified) .

7 Effect of Vanädium on the Low-Temperature Notch Strength of Niobium-Vanadium Alloys (KS-59992, Unclassified) . • . . 14

8 Transgranular Cracks Adjacent to the Fracture Surface (KS-59993, Unclassified) . . . • . . • . . . . . 15

9 Electron Fractographs of Niobium-6 wt \% Vanadium (KS-59994,

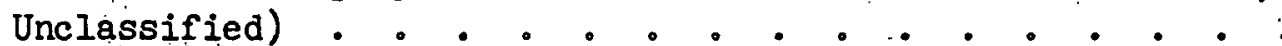

10 Eleotron Fractographs of Niobium-4 wt \% Vanadium Tested at -100C, 70\% Reduction in Area (KS-59995, Unclassified) . . .

11 Effect of Notches on Ductile-to-Brittle Transition Temperature (KS-59996, Unclassified)

12 Variation of the Low-Temperature Yield Stress of NiobiumVanadium Alloys as a Function of Vanadium and Temperature (KS-59997, Unclassified)

13 Notch Sensitivity of N1oblum-Vanadium Alioys in Temperature Range of -200 to $25 \mathrm{C}$ (KS-59998, Unclassified)

14 Effect of Strain Rate on Ductile-to-Brittle Transition Temperature of Niobium-2 and -6 wt \% Vanadium (KS-59999, Unclassified) 
No.

15 Effect of Strain Rate on Low-Temperature Notch Strength of Niobium-2 and -6 wt. \% Vanadium (KS-62000, Unclassified) . 23

16 Effect of Nitrogen and Oxygen on Ductile-to-Brittle Transition Temperature (KS-62001, Unclassified) . . . . . . . 24

17 Effect of Nitrogen or Oxygen on Notch Strength (KS-62002, Unclassified) 


\section{ABSTRACT}

The ductile-to-brittle transition temperatures of niobiumvanadium alloys of $2,4,6$, and $8 \mathrm{wt}$. \% vanadium were investigated in the temperature range of -253 to 100C. Notched tensiletesting was the testing method used. The transition temperature, arbitrarily defined as that temperature where the reduction in area was $35 \%$, was increased by the addition of vanadium to niobium - the relationship being linear up to $6 \mathrm{wt}$. \% vanadium. The temperature range over which the alloys changed from ductile to brittle behavior varied directly with vanadium content. When tested in the unnotched condition, these alloys did not undergo a ductile-to-brittle transition as defined in this study, nor did they become notch-sensitive at temperatures of $-196 \mathrm{C}$.

Notched specimens were tested at cross-head motions of 0.025 and $2.0 \mathrm{in./min}$ to study the strain-rate sensitivity of niobiumvanadium alloys. Most of the data indicated that the mechanical properties of niobium-vanadium were insensitive to strain rate.

The addition of 500-ppm nitrogen and 1500-pun oxygen to niobium -2 and -4 wt. $\%$ vanadium alloys caused pronounced increases in the ductile-to-brittle transition temperature of the niobium-vanadium. Nitrogen was found to be more potent than oxygen as a strengthener. The influence of both nitrogen and oxygen on the mechanical properti.es was greater in the alloys of higher vanadium content.

In a study of the microstructure adjacent to the fracture surface, light microscopy indicated that the propagation of a crack in the alloys studied progressed transgranularly. Electron fractographs of selected specimens revealed that the predominant mode of failure was cleavage. 
THIS PAGE

WAS INTENTIONALLY

LEFT BLANK 


\section{ACKNOWLEDGMENT}

The author wishes to express his appreciation to J. W. Harrison for the fabrication of the alloys and to L. S. Deluca for preparation of the electron fractographs.

Thanks also are extended to Dr. A. P. Beard, under whose direction this research was performed, for his many suggestions and criticisms. 
DUCTILE-TO-BRITTLE TRANSITION OF NIOBIUM-VANADIUM ALLOYS AS AFFECTED : BY NOTCHES, STRAIN RATE, NITROGEN, AND OXYGEN

\author{
C. D. Calhoun
}

INTRODUCTION

Niobium has a number of properties which make it attractive for nuclear applications. Its preirradiation mechanical and corrosion properties are improved through the addition of alloying elements. ${ }^{1-9}$ of the alloying elements studied, vanadium appears to be one of the most beneficial since it forms a continuous solid solution with niobium. Because of the complete solid solubility of niobium and vanadium, alloys of these elements have, properties relatively independent of heat-treatrient. However, postirradiation mechanical tests of niobium and niobium $\div 6$ wt. \% vanadium samples irradiated under comparable conditions indicated that niobium-6 wt. \% vanadium exhibited a higher level of irradiation damage than did niobium. 4

It was considered desirable to investigate the ductile-to-brittle transition behavior of niobium as affected by vanadium content, impurities, and stress conditions. Such information would facilitate design and specification of the optimum alloy for a particular application.

A previous investigation of the effect on niobium of various substitutional solutes revealed that molybdenum and tungsten caused significant increases in the transition temperature. 5 Titanium had little effect on the transition temperature, and zirconium and hafnium appeared to be somewhat intermediate in their effect. Some indirect experimental data indicated that the behavior of vanadium and zirconium would be similar, 5 but an actual investigation of the effect of vanadium on the ductile-tobrittle transition temperature remained to be accomplished.

With additions of vanadium to niobium, the niobium lattice contracts. The effects of lattice contraction on the notch and strain-rate sensitivity of niobium remained to be determined. It would be speculated, however, that the effect of interstitials would become more drastic and, in general, would more extensively inhibit plastic deformation in the contracted lattice than in niobium:

Therefore, the purpose of this investigation was: (1) to establish the relationship between the vanadium content and the ductile-to-brittle transition temperature in niobium-vanadium alioys containing up to 8 wt. :\% vanadium, (2) to study the effect of notches, strain rate, and interstitials on the transition temperatures of niobium-vanadium alioys, and (3) to 
compare the magnitude of the effects of these variables as a function of vanadium content.

EXPERIMENTAL PROCEDURE

Alloy Preparation

Initially, two alloys of nominal niobium -2 and -8 wt. $\%$ vanadium were double-arc-melted and extruded to $\sim 1-i n$-diam bars. Prior to extrusion, these alloys were heat-treated for $1.5 \mathrm{hr}$ at $1775 \mathrm{C}$ in an argon atmosphere; one die was used for two extrusions. After extrusion, the surface contamination was removed by grinding, and the material was swaged to a $0.35-i n .-d i a m$ rod. Attempts to swage these alloys resulted in a $25 \%$ yield for the niobium-2 wt. $\%$ vanadium alloy and a zero yleld for the niobium-8 w.t. \% vanadium alloy.

The heat-treatment prior to extrusion was then reduced to $0.75 \mathrm{hr}$ at $1700 \mathrm{C}$, and one die of $\sim 1.25-i n$. diameter was used for each extrusion. Since these extrusions were of considerably better quality than those initially swaged, alloys of niobium -4 and -6 wt. \% vanadiun were then fabricated by this procedure without difficulty. The niobium -8 wt. \% vanadium alloy remained difficult to swage without the formation of end cracks which propa-.. gated along the length of the bar during further swaging. Heat-treatments at temperatures up to $1400 \mathrm{C}$ did not alleviate the difficulty. The yield of useful material from this alloy was only about $20 \%$.

Addition of Interstitials

In the study of the effect of nitrogen and oxygen on the ductile-tobrittle transition temperature of ninbium-vanadium alluys, it was necessary to establish the base concentration of such interstitials in the material. The chemical analysis of the material in the as-swaged condition is given in Appendix A. Oxygen and nitrogen concentrations in niobium-vanadium were increased to 1500 and $500 \mathrm{ppm}$ (by weight), respectively. The oxygen was added to a closed system containing the swaged rod by using a sleverts apparatus. The rod was heated to $900 \mathrm{C}$ for $6 . \mathrm{hr}$ and was assumed to absorb all the oxygen in the system.

The nitrogen was added by permitting the alloy to react in slightly less than an atmosphere of nitrogen at 1200C. (The relationship of $\mathrm{mg}$ $\mathrm{N}_{2} / \mathrm{cm}^{2}$ vs time at $1200 \mathrm{C}$ for these alloys had been previously determined. ${ }^{6}$ ) The material was then homogenized for 17 days at $1200 \mathrm{C}$ in a residual airpressure of $\sim 10^{-5} \mu$. . Hardness traverses following this heat-treatment indicated that the material was homogeneous. To further verify the homogeneity of the material and to determine its interstitial concentration, chips were machined from the center and surface of the rod for chemical analysis. The results of these analyses are given in Table 1. 


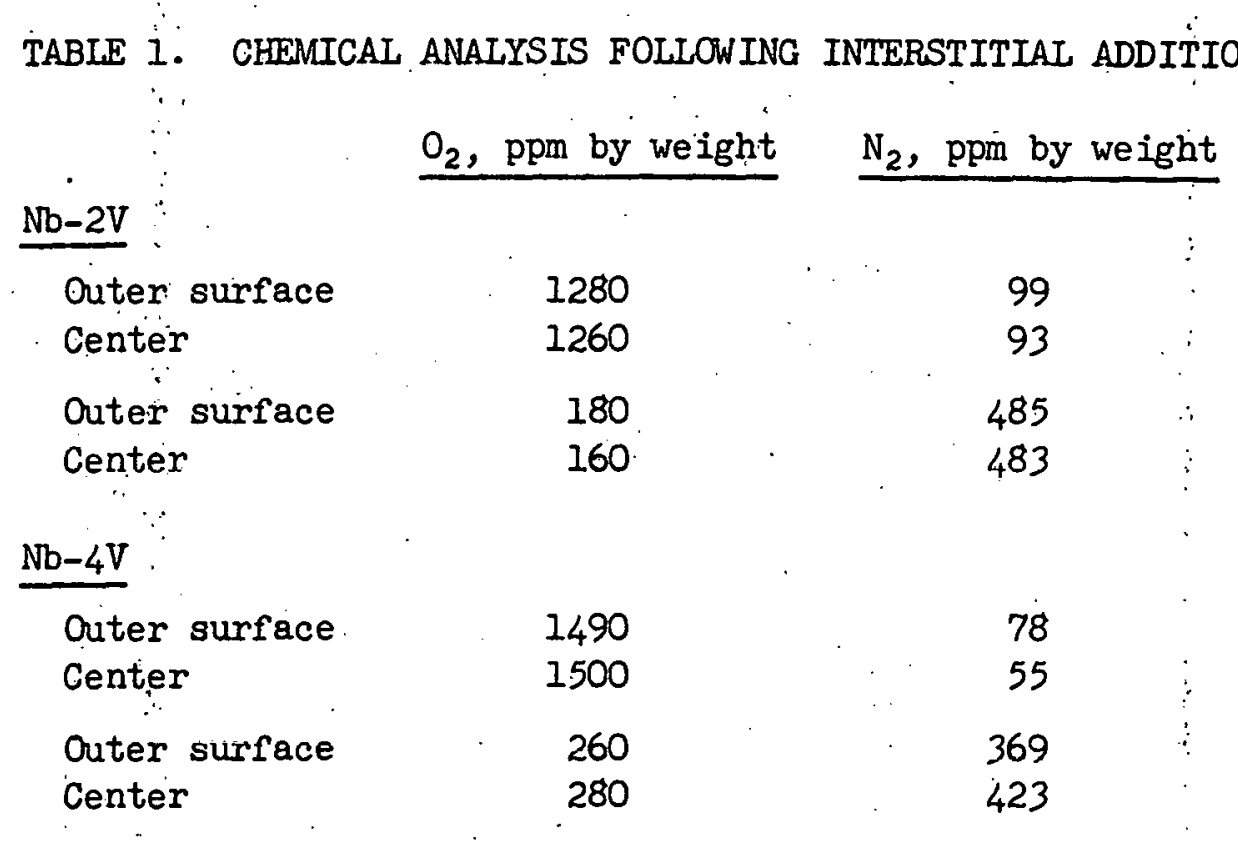

Preparation of Tensile Specimens

Notched and unnotched tensile specimens (Figure 1) were machined from the swaged rod. The diameter of the specimens at the notch root corresponded to the diameter of the unnotched specimens. The 60-deg notch, with a root radius of 0.006 in., reduced the cross-sectional area by $50 \%$.

$\because$ Prior to testing, the specimens were heat-treated for $1 \mathrm{hr}$ at $1200 \mathrm{C}$ for recrystallization; the specimens for the interstitial studies were heattreated for relief of machining stresses. A chemical analysis of the control specimens following this heat-treatment is given in Table 2. The average grain size in the recrystallized material was $30 \mu$ in diameter (Figure 2). The average grain size at the termination of the homogenization heat-treatment was established at $62 \mu$ (Figure 3). The grain growth during the extended homogenization heat-treatment (17 days at 1200C) does not appear extensive enough to confound the results.

Because of the propagation of end cracks during the swaging operation, some of the specimens contained longitudinal cracks. The dye-penetrant method, selected as the nondestructive test for identifying the cracked specimens, was very satisfactory; 17 of 150 specimens were rejected.

Testing

The low-temperature tensile tests ( $-253 \mathrm{C}$ to $25 \mathrm{C}$ ) were performed in refrigerants of liquid hydrogen $(-253 \mathrm{C})$, liquid nitrogen (-196C), Freon-12 $(-75$ to $-150 \mathrm{C})$, and ethyl alcohol ( -50 to $75 \mathrm{C}$ ) employing a Tinus-0lson 


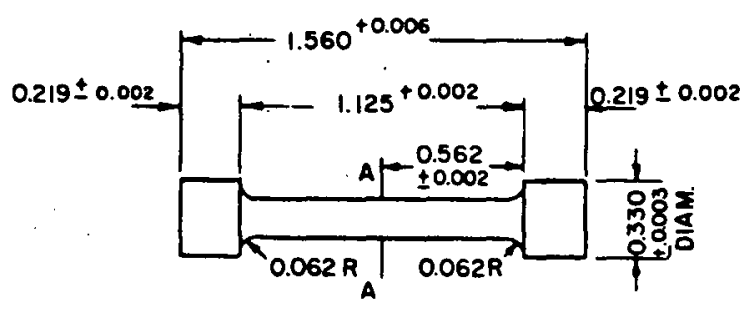

(SEE NOTCHED ANO UNNOTCHED SPECIMENS BELOW)

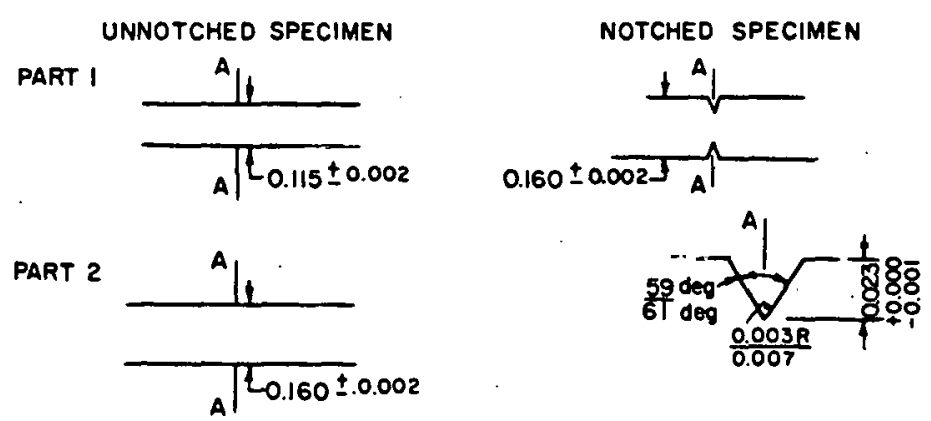

FIGURE 1. Schematic of Tensile Specimens.

KS-59986 Unclassified

TABLE 2. CHEMICAL ANALYSIS AFTER RECRYSTALLIZATION

HEAT-TREATMF.NT (l hr at 120M::)

\begin{tabular}{|c|c|c|c|c|}
\hline \multirow[b]{2}{*}{ Elements } & \multicolumn{4}{|c|}{ Ingot Number } \\
\hline & $A-216$ & $A-218$ & $A-219$ & $A-220$ \\
\hline$v$, wt \% & $\sim 2$ & $\sim 4$ & $\sim 6$ & $\sim 8$ \\
\hline $0^{*}$ & 165 & 160 & 240 & 305 \\
\hline$N^{*}$ & 142 & 133 & 133 & 105 \\
\hline $\mathrm{H}^{*}$ & 5 & 3 & 36 & 20 \\
\hline
\end{tabular}

*ppm by weight

tensile-testing machine. The reduction in area was determined by an optical comparator having a magnification of $10 \mathrm{X}$ and equipped with a micrometer. stage.

Vacrographs of the fracture surf'ace were taken perpendicular and transverse to the fracture surface to reveal the plastic derormation as a function 


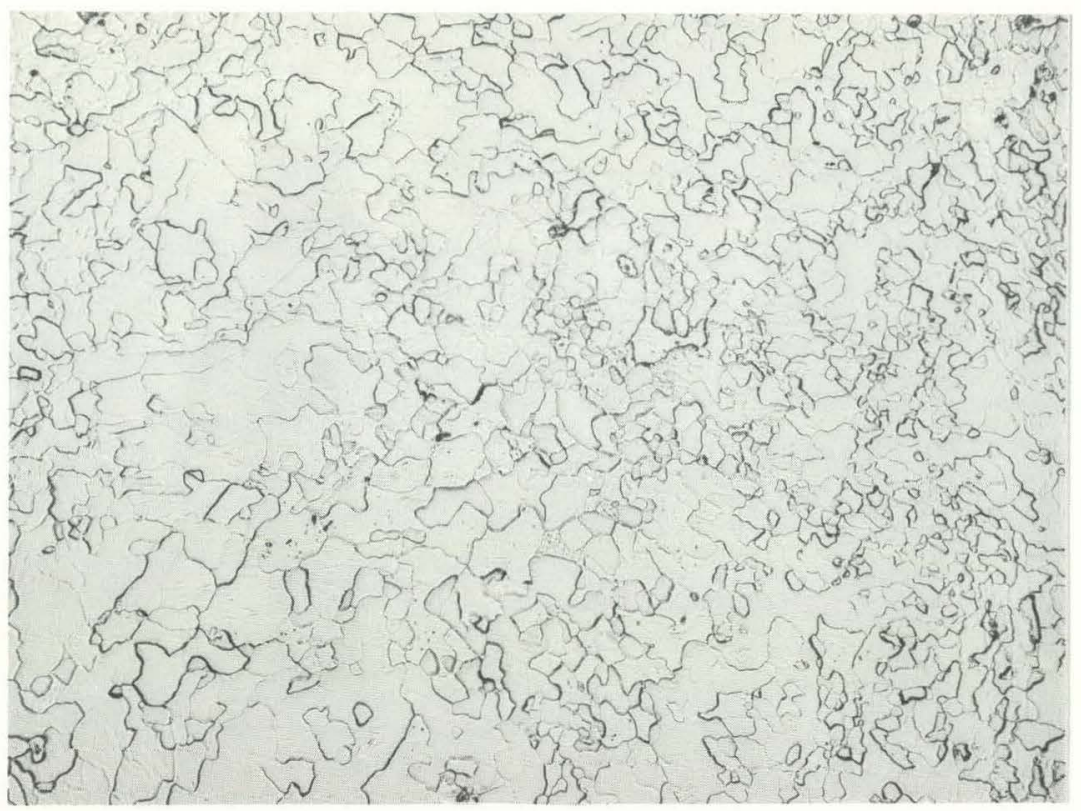

FIGURE 2. Microstructure of Niobium-Vanadium after Recrystallization Anneal of $1 \mathrm{hr}$ at $1200 \mathrm{C}$.

KS-59987

Unclassified

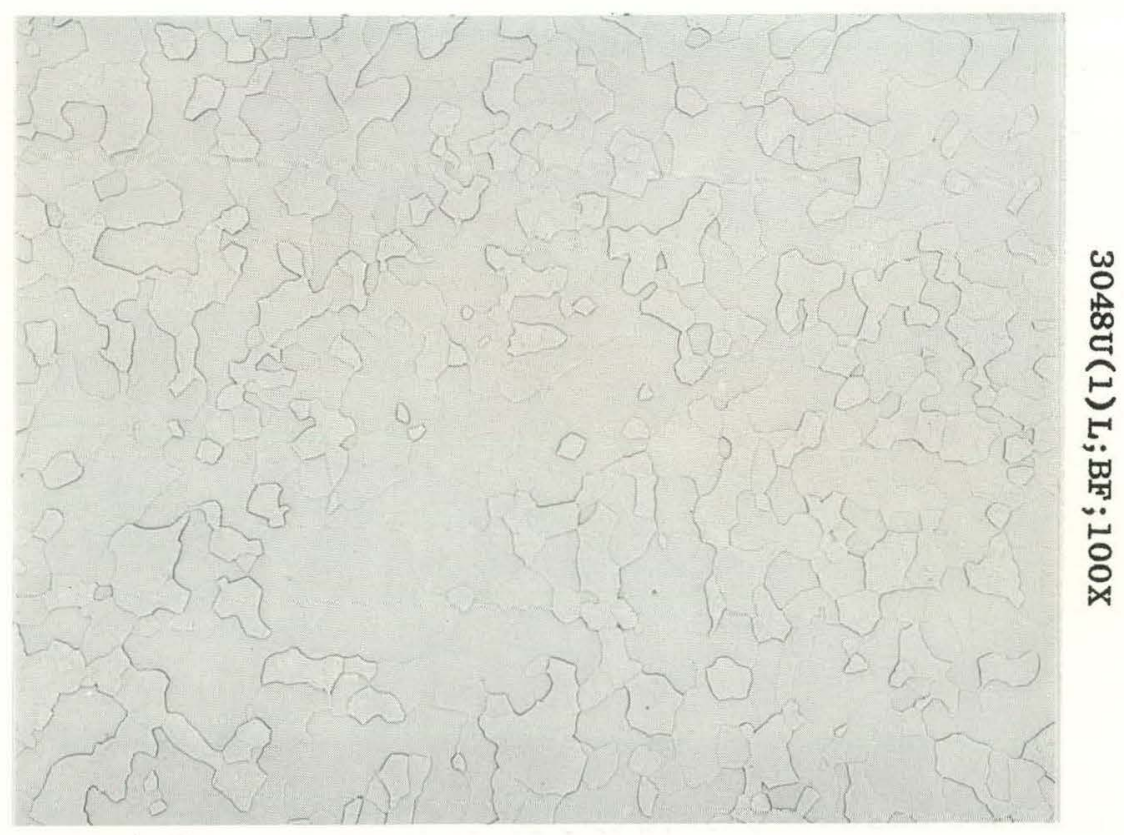

FIGURE 3. Representative Microstructure of Niobium-Vanadium Alloys after Homogenization Heat Treatment of 17 days at $1200 \mathrm{C}$. 
THIS PAGE

\section{WAS INTENTIONALLY LEFT BLANK}


of temperature (Figure 4). One-half of the gage section was mounted and polished to its longitudinal centerline. (A photomicrograph of the microstructure adjacent to the fracture is shown in Figure 5.) The etchant used was $50 \mathrm{ml} \mathrm{HNO}_{3}, 50 \mathrm{ml} \mathrm{H}_{2} \mathrm{O}$, and 30 drops of hydrofluoric acid.

The electron fractographs were taken with a JEM-6A electron microscope. A two-stage cellulose acetate-carbon replica, shadowed with carbonplatinum at $45 \mathrm{deg}$, was used.

\section{RESULTS}

Effect of Vanadium Additions

The effect of vanadium on the ductile-to-brittle transition temperature $^{*}$ of niobium (Figure 6, A and B) was determined by tensile tests performed on notched specimens in the temperature range of -196 to $25 \mathrm{C}$. The resulting data indicated that the transition temperature was increased from $-215 \mathrm{C}$ for the niobium $-2 \mathrm{wt}$. \% vanadium alloy to $-75 \mathrm{C}$ for the niobium-8 wt. \% vanadium alloy. The increases in transition temperature as a function of vanadium content (Figure 6B) remained linear up to 6 wt. \% vanadium. In this range of vanadium content, the transition temperature was increased by $30 \mathrm{C}$ per 1 wt. \% vanadium. Increasing the vanadium content from 6 to 8 wt. \% caused an increase of $12 \mathrm{C}$ per 1 wt. \% vanadium. With increasing vanadium content, the alloys exhibited a transition from ductile to brittle behavior over a larger temperature range.

The low-temperature notch strength of niobium-vanadium alloys increased with decreasing temperature and increasing vanadium (Figure 7).

The degree of plastic deformation preceding failure, for niobium-6 wt. \% vanadium, varied inversely with temperature (Figure 4 ). The photomicrographs in Figure 8 revealed that cracks in niobium-vanadium propagated transgranularly.

The electron fractographs indicated that the predominant mode of fuilure in these alloys was cleavage (Figures 9 and 10). In Figure 9C, a fractograph of niobium -6 wt. \% vanadium tested at room temperature, and in Figure 10 , fractographs of niobium -4 wt. \% vanadium at $-100 \mathrm{C}$, there are indications of the starting of quasi-cleavage. Even in these specimens, however, the predominant failure was by cleavage.

Effect of Notches

Notches adversely affected the ductility of niobium-vanadium alloys in the temperature range -196 to $25 \mathrm{C}$ (Figure 11), the effect being more pronounced in the alloys of higher vanadium content.

* Defined as that temperature where the reduction in area is $35 \%$. 
The ductility of the unnotched tensile specimens was not adversely affected in the temperature range investigated. The niobium-8 wt. \% vanadium had $765 \%$ reduction in area at $-150 \mathrm{C}$. The ductility decreased with increasing vanadium content and decreasing temperature. The yield stress varied directly with vanadium content and inversely with temperature (Figure 12).

From Figure 13 it can be seen that the notch sensitivities (ratio of the notched to the unnotched strength) of the niobium-vanadium alloys were about 1.5. Notch sensitivity seemed to vary only slightly with temperature and/or vanadium content within the boundaries of these tests.

\section{Effect of Strain Rate}

Figures 14 and 15 show the effect of an 100 -fold increase (0.025 to $2.0 \mathrm{in.} / \mathrm{min}$ ) in cross-head motion on the mechanical properties of the notched tensile specimens. Figure 14 shows an apparent absence of any large or systematic variation of ductility with strain rate. In the temperature range above $-150 \mathrm{C}$, the niobium $-6 \mathrm{wt}$. \% vanadium showed an increased ductility with the faster strain rate; however, the magnitude of this increase was relatively small. The tests at $-253 \mathrm{C}$ for the niobium-2 wt. \% vanadium resulted in a $5 \%$ reduction in area for the slow strain rate and a $43 \%$ reduction in area for the fast strain rate.

The notch strength was rather insensitive to strain rate for the two niobium-vanadium alloys investigated (Figure 15). Note that in the tests at $-253 \mathrm{C}$ for the niobium-2 wt. \% vanadium, the ductility was influenced by the change in strain rate, but the magnitude of the notch strength remained the same.

Effect of Interstitials

The relationships between the ductility of niobium-vanadium and niobiumvanadium plus a nominal 500-ppm nitrogen or $1500-p p m$ oxygen are shown in Figure 16. The two alloys investigated were niobium-2 wt. $\%$ vanadium and niobium-4 wt. \% vanadium. The concentrations of nitrogen and oxygen present as impurities before the interstitial additions are shown in Appendix A.

The ductility varied inversely with interstitial concentration in the temperature range investigated. The addition of a nominal 500-ppm nitrogen and 1500-ppm oxygen to niobium -2 wt. \% vanadium increased the ductile-tobrittle transition temperature by 120 and 1500 , respectively. Equivalent additions to niobium -4 wt. \% vanadium increased the transition temperature by 185 and $225 \mathrm{C}$ for the nitrogen and oxygen, respectively.

The data points for all graphs in this investigation are representative of single tests and, in the case of the niobium-4 wt. \% vanadium with the 340-ppm nitrogen addition (Figure 16B), the degree of scatter was considerable. However, the indicated curve is believed to be representative. 

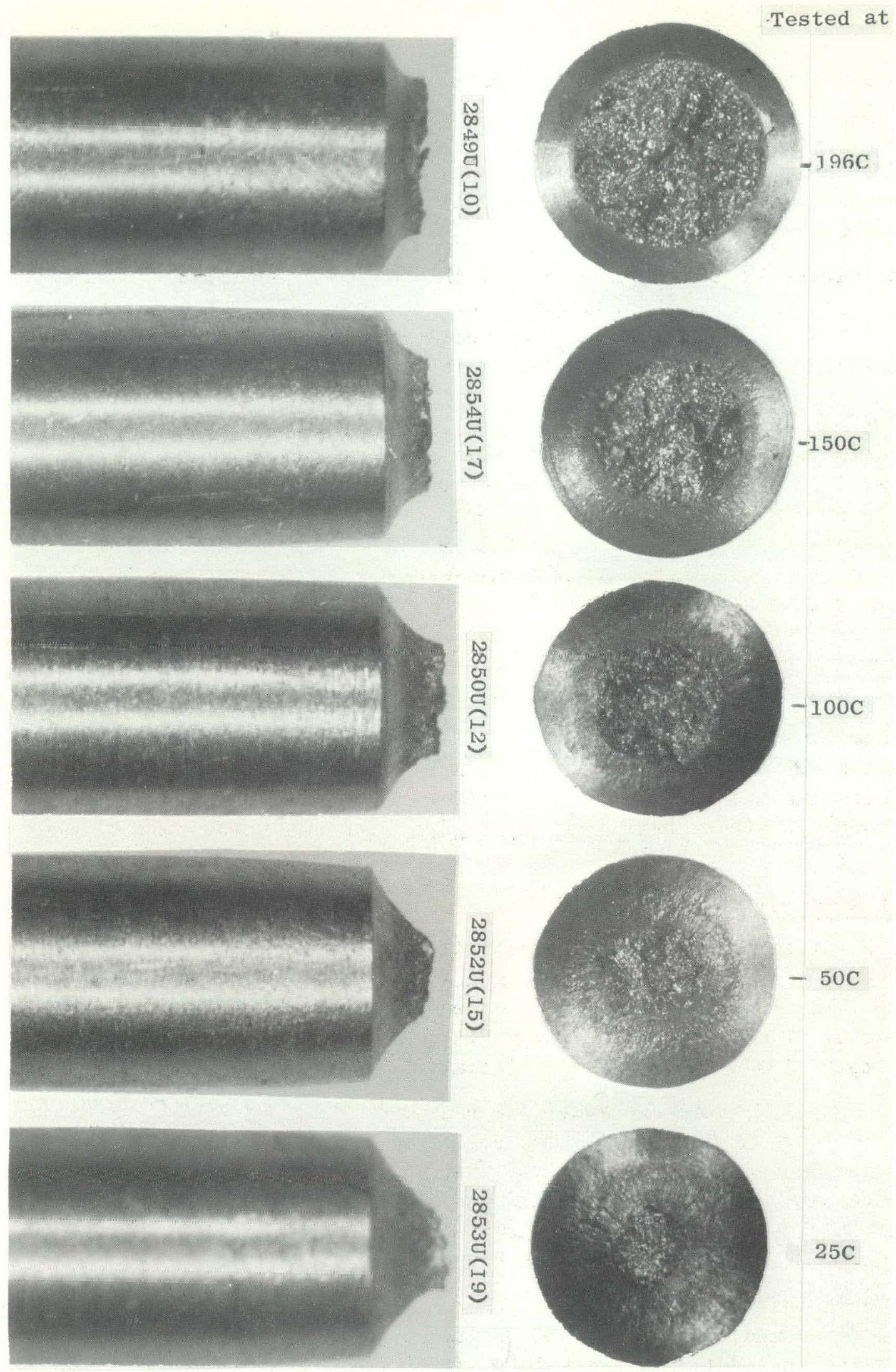

FIGURE 4. Variation of Plastic Deformation as a Function of Temperature for N1obium-6 wt \% Vanadium. 


\section{THIS PAGE}

\section{WAS INTENTIONALLY \\ LEFT BLANK}




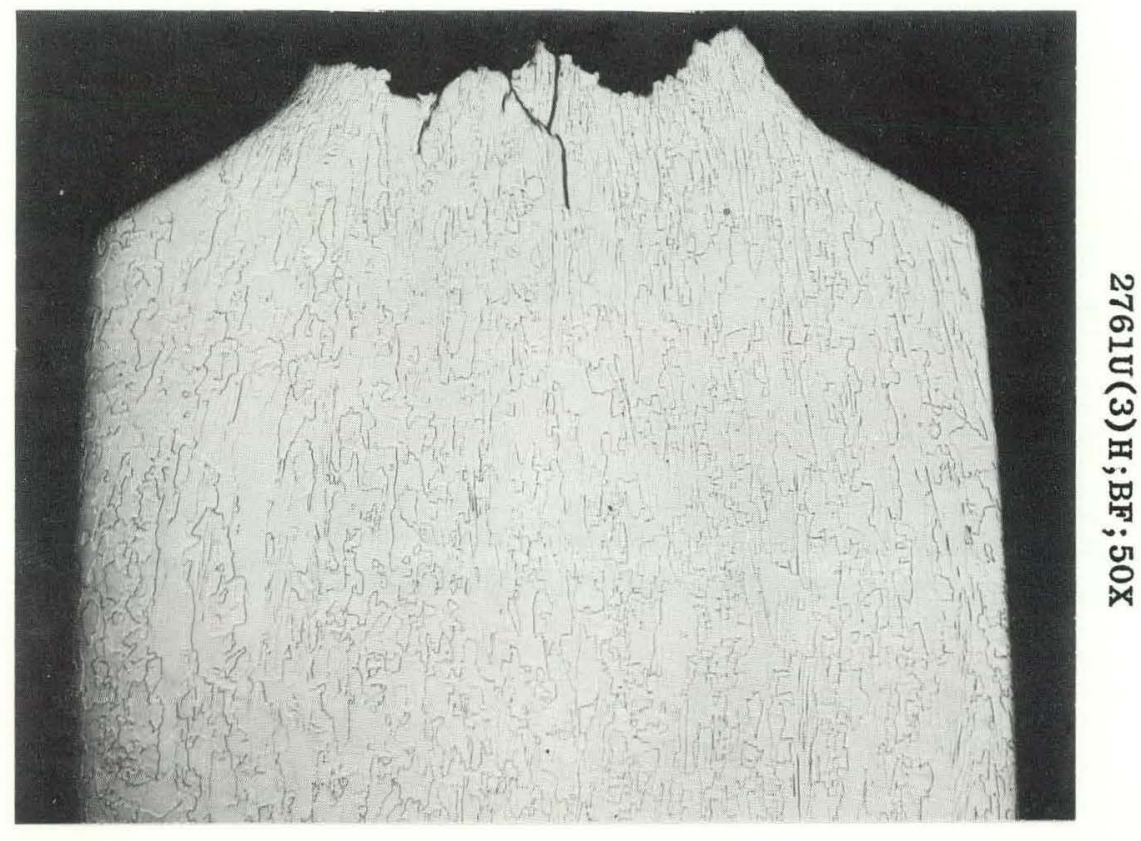

FIGURE 5. Microstructure of Niobium-Vanadium Tensile Specimens.

KS-59990

Unclassified 


\section{THIS PAGE}

\section{WAS INTENTIONALLY \\ LEFT BLANK}




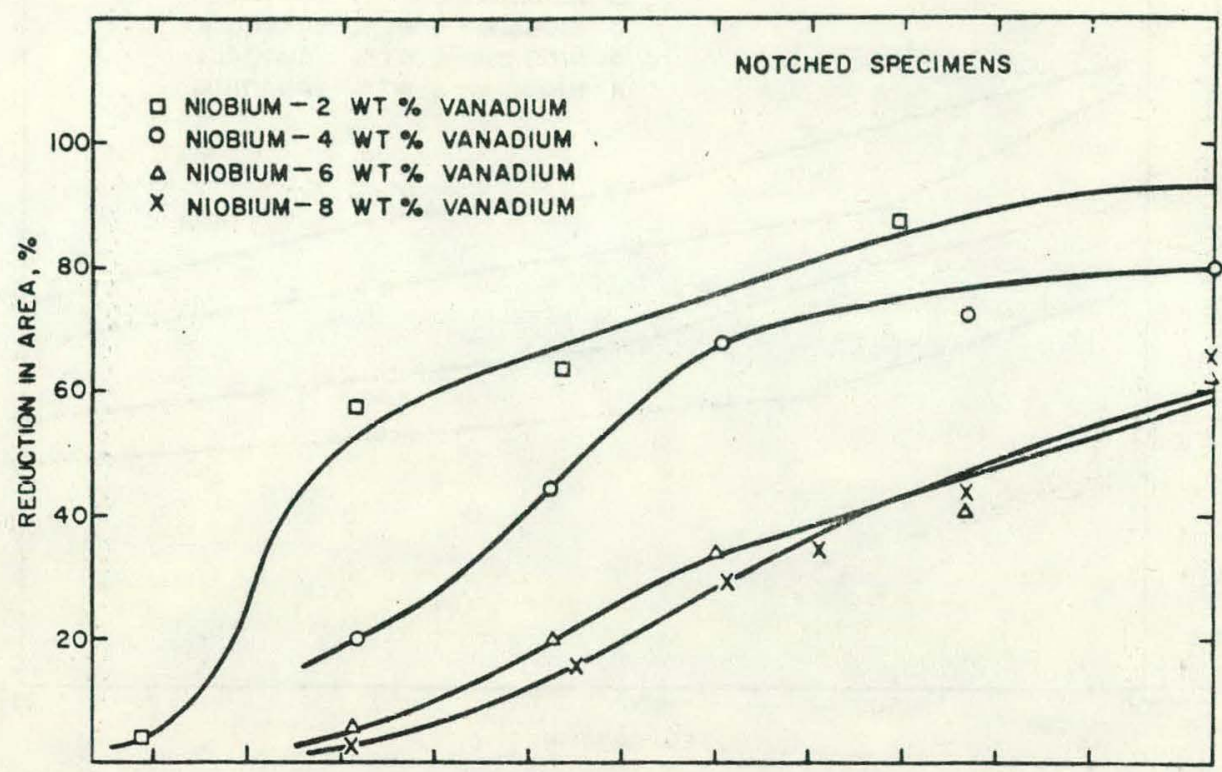

A. Temperature vs Reduction in Area

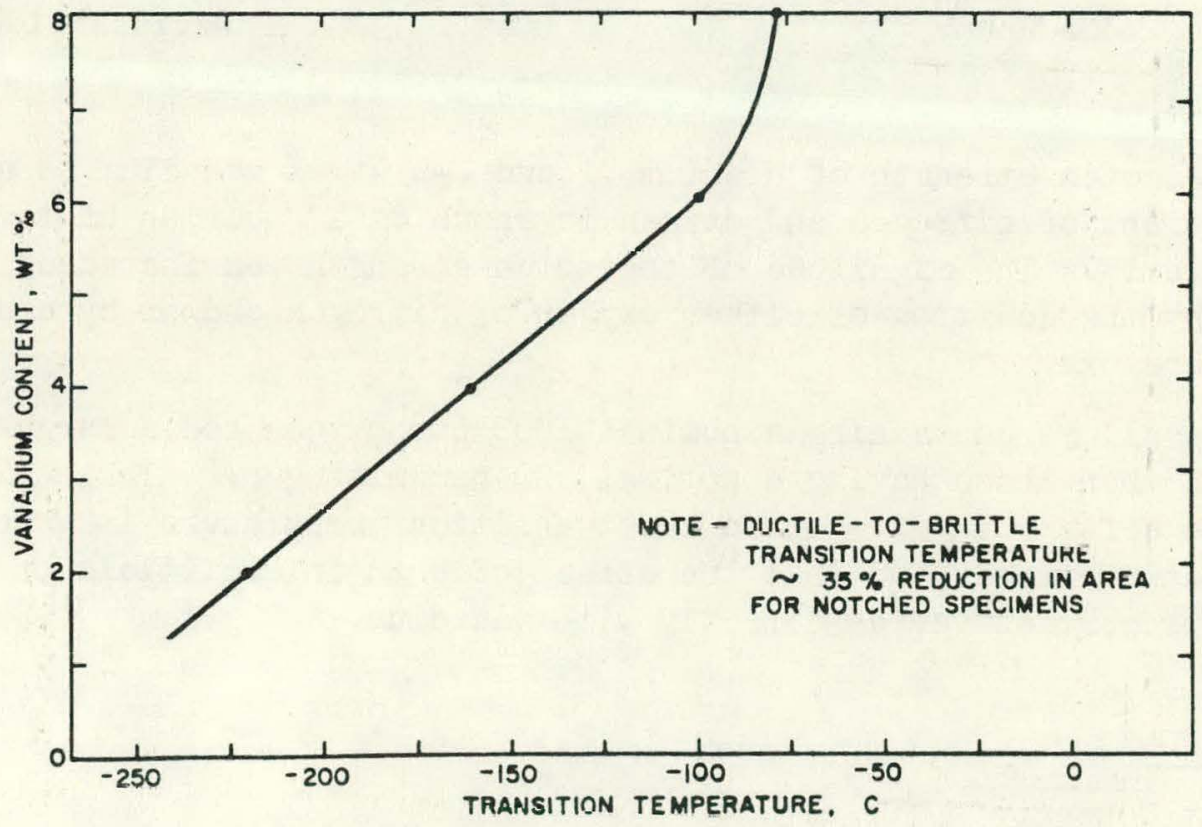

B. Transition Temperature vs Vanadium Content

FIGURE 6. Effect of Vanadium on Ductile-to-Brittle Transition Temperature of Niobium-Vanadium Alloys. KS-59991

Unclassified 


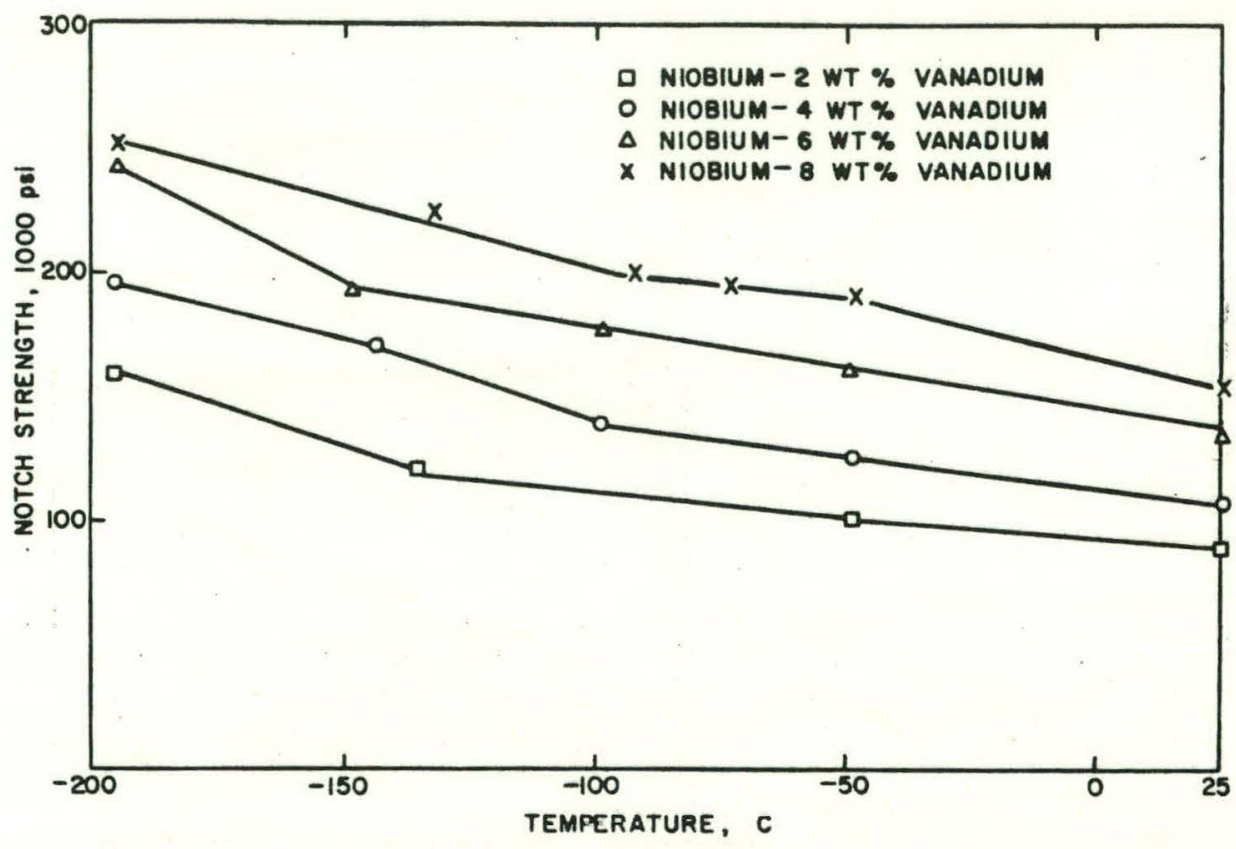

FIGURE 7. Effect of Vanadium on Low-Temperature Notch Strength of Niobium-Vanadium Alloys.

KS-59992

Unclassified

The notch strength of niobium-2 and $-4 \mathrm{wt} . \%$ vanadium as altered by additions of nitrogen and oxygen is shown as a function of temperature in Figure 17. The magnitude of the notch strength was increased in both alloys by the addition of either oxygen or nitrogen and/or by a decrease in temperature.

The alloys containing a nominal 1500-ppm oxygen had a larger notch strength than those having a nominal 500-pprn nitrogen. * Table 3 shows that the effect of nitrogen on the transition temperature is more pronounced than that of oxygen, and that the effect of both interstitials on the mechanical properties varies directly with vanadium.

\section{DISCUSSION}

\section{Vanadiun Cuntent}

When subjected to a stress at progressively lower temperatures, niobium undergoes a transition from ductile to brittle behavior. This phenomenon is common to those metals with body-centered cubic (bcc) structures. When interstitials (oxygen, nitrogen, hydrogen, and carbon) are added to these

*The concentration of nitrogen and oxygen likely to be maintained in solid solution is $\sim 300$ and $\sim 1000 \mathrm{ppm}$, respectively. ${ }^{7}$ 


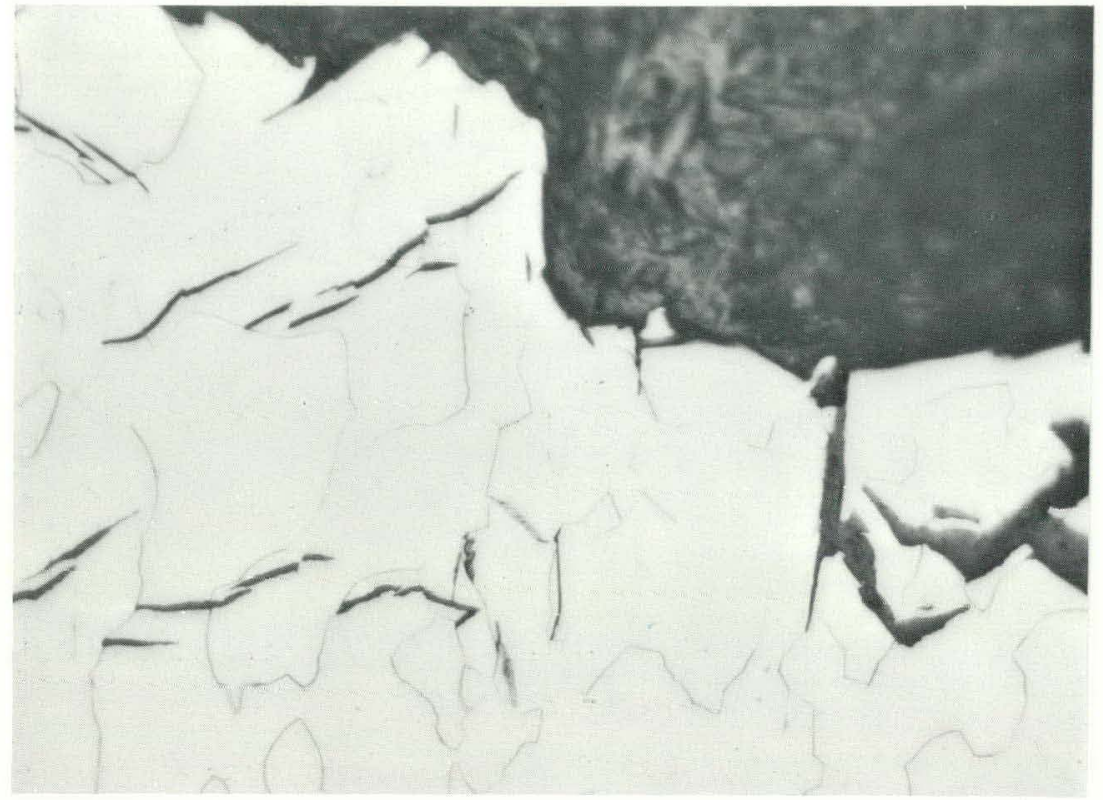

崩

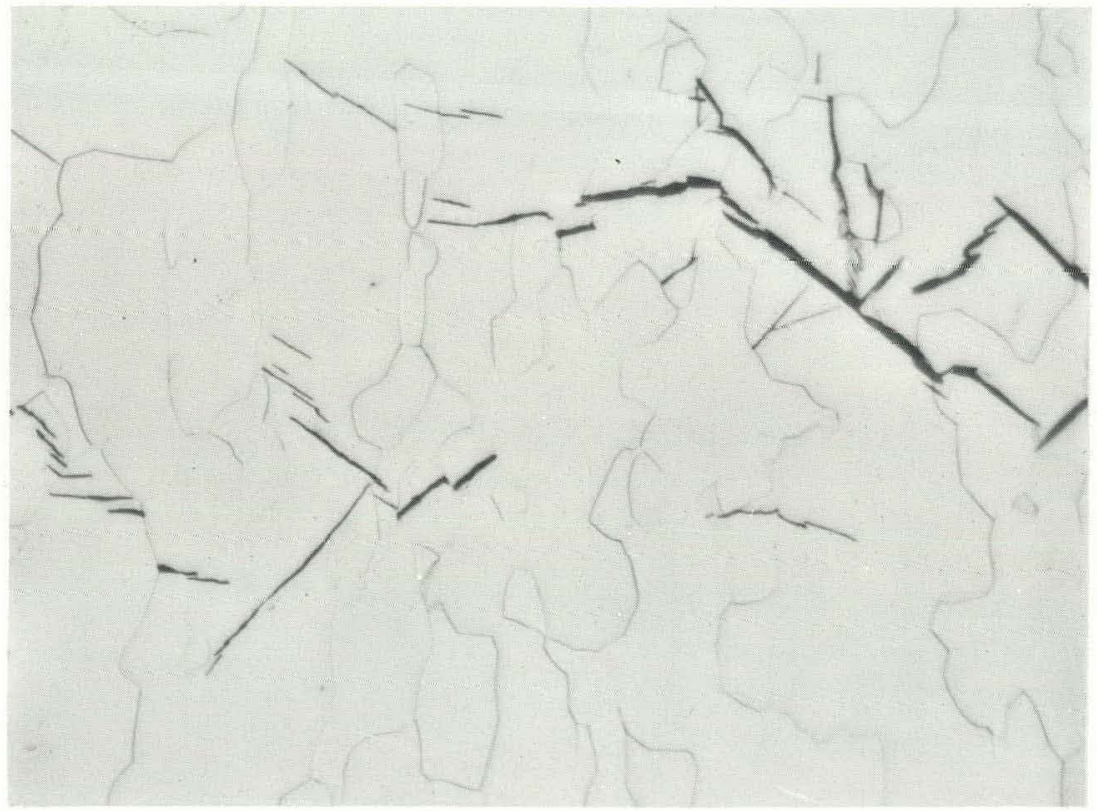

FIGURE 8. Transgranular Cracks Adjacent to the Fracture Surface.

KS-59993

Unclassified 
THIS PAGE

\section{WAS INTENTIONALLY LEFT BLANK}



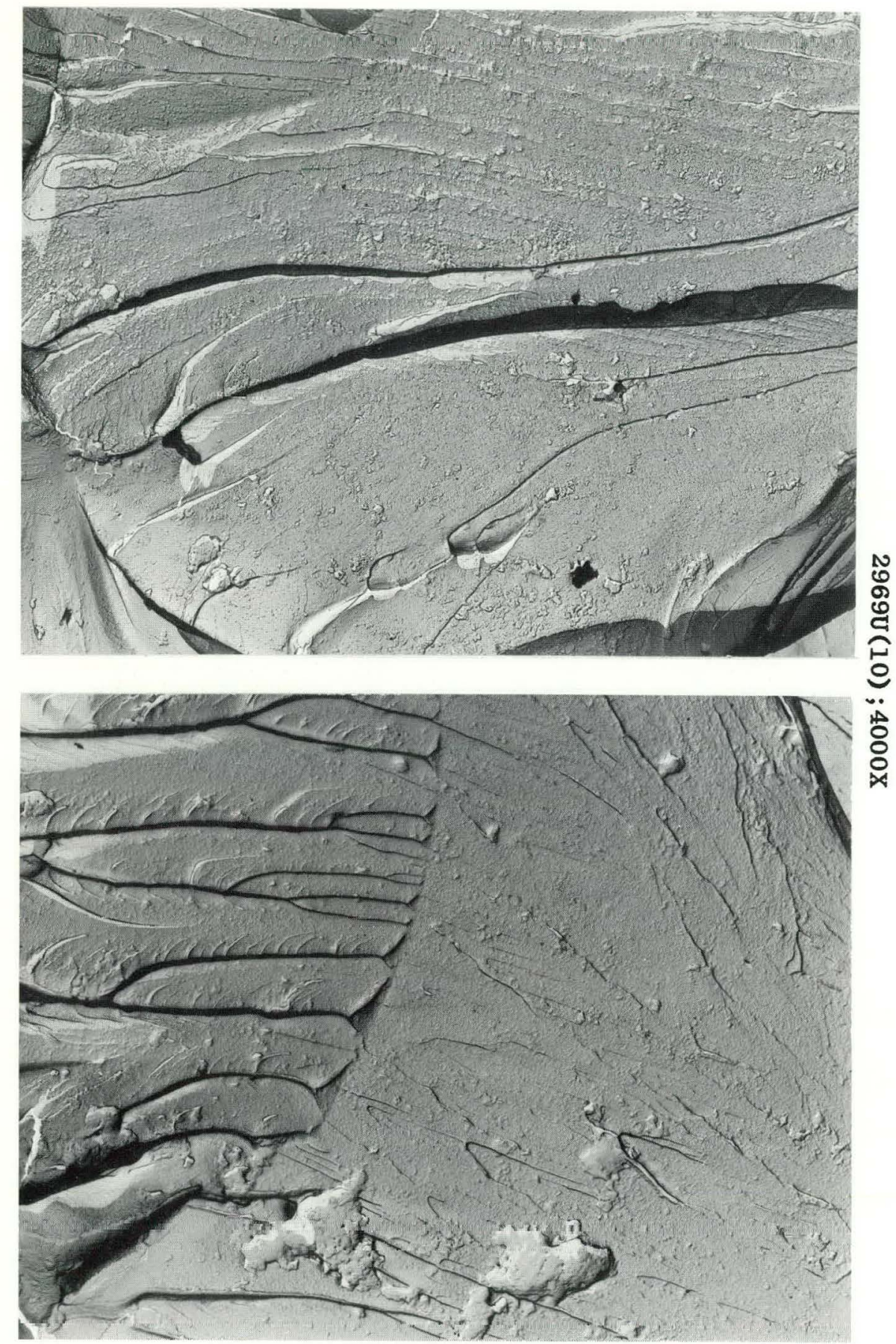

A. Temperature: $-196 \mathrm{C}$ Reduction in Area: $5 \%$
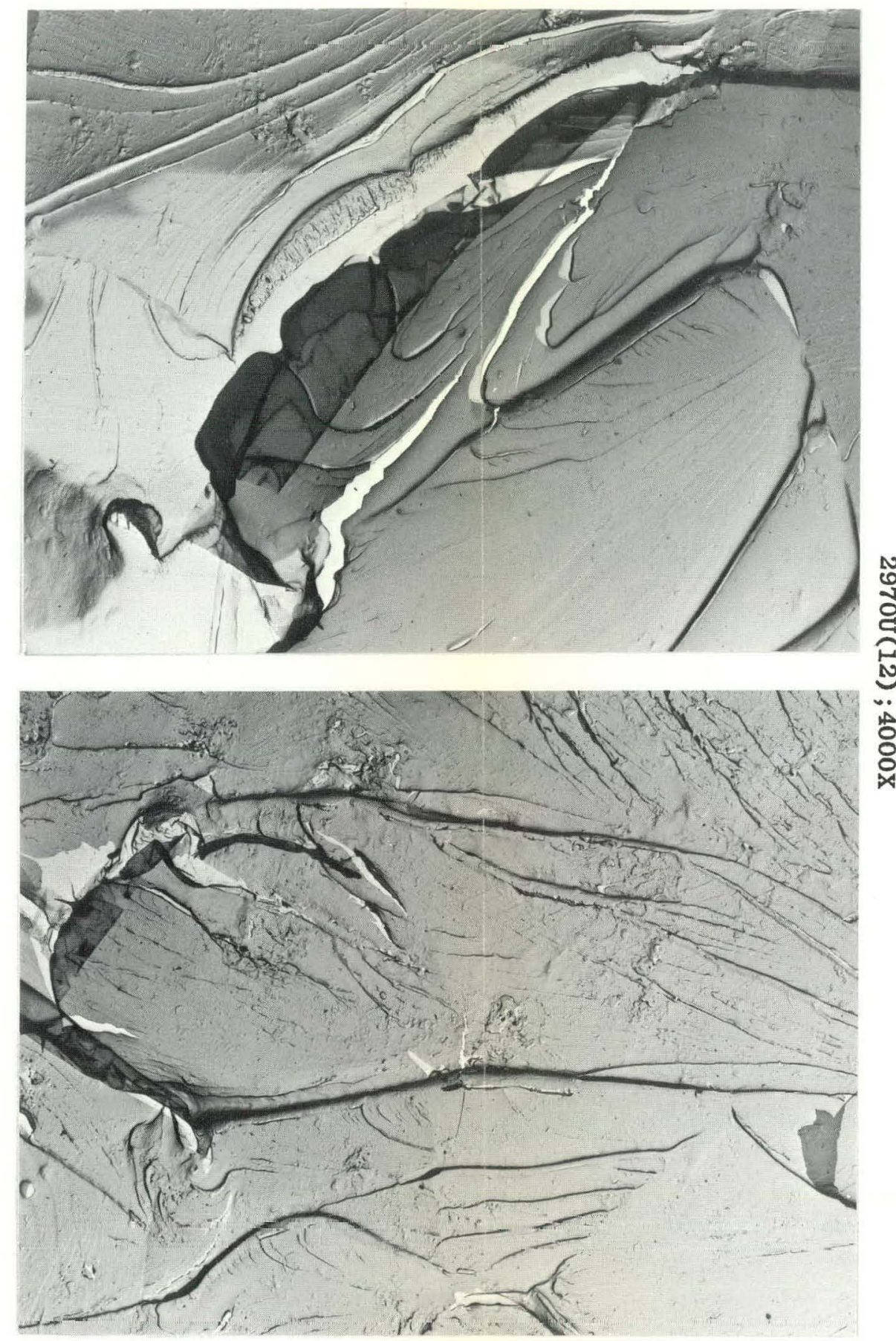

B. Temperature: $-100 \mathrm{C}$

Reduction in Area: 35\%

FIGURE 9. Electron Fractographs of Niobium-6 wt \% Vanadium.
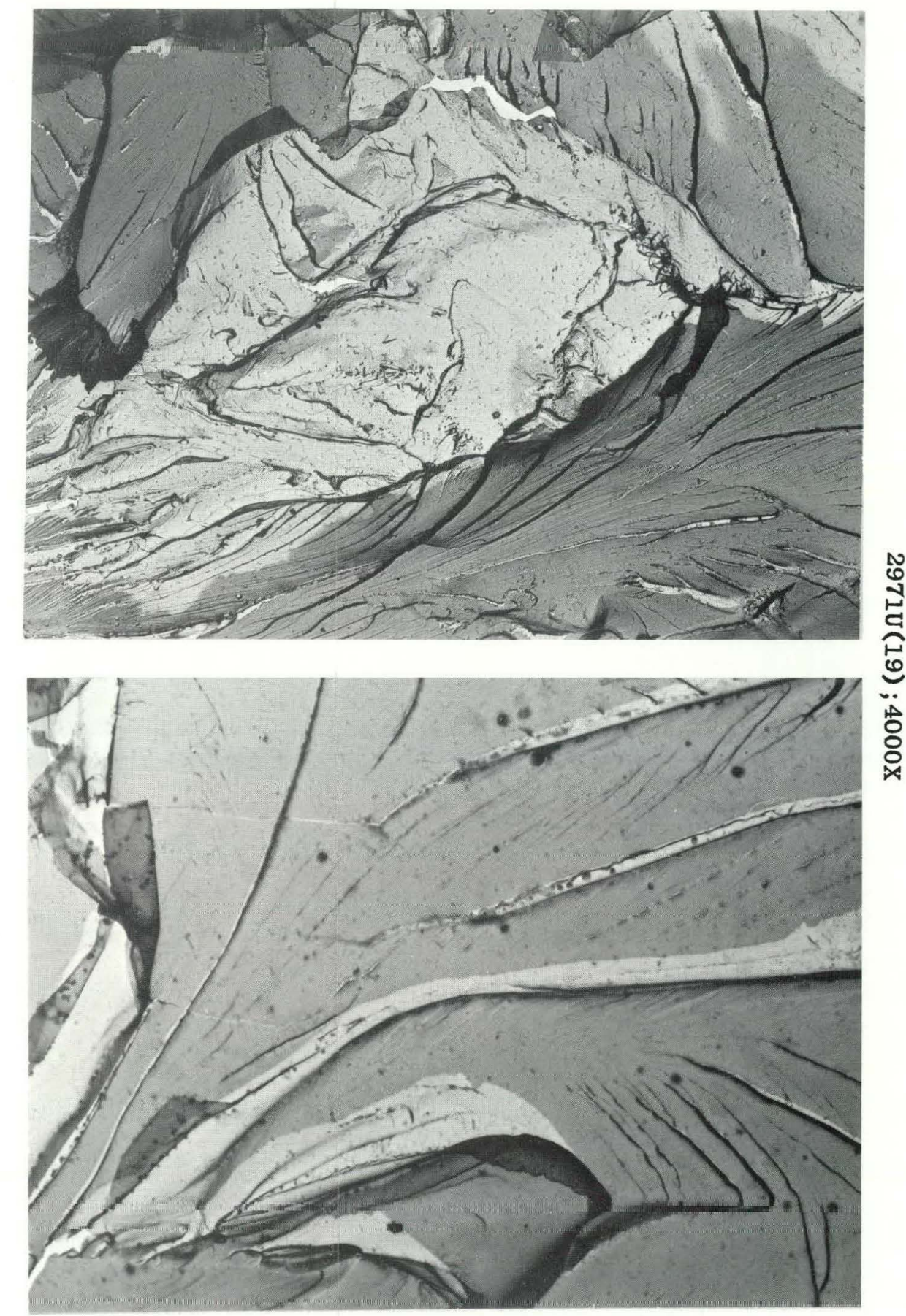

C. Temperature: $25 \mathrm{C}$ Reduction in Area: $64 \%$ 
THIS PAGE

WAS INTENTIONALLY

LEFT BLANK 


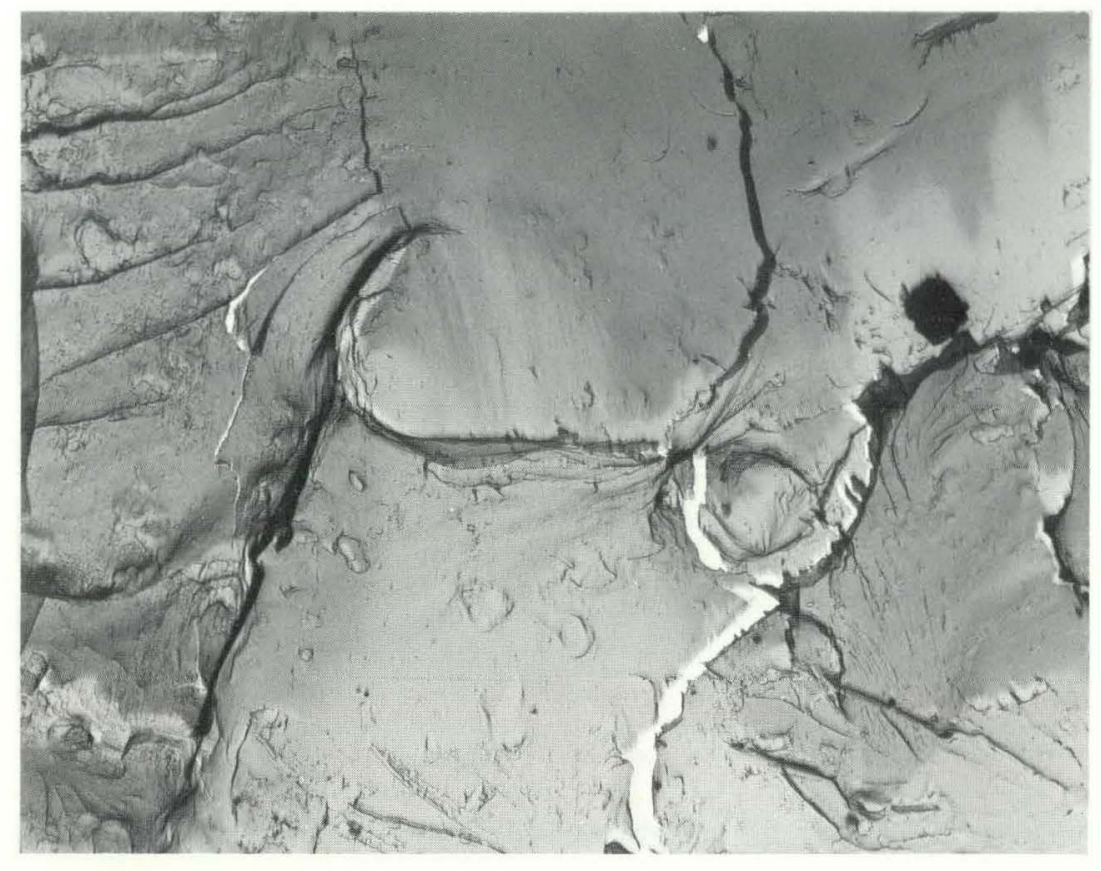

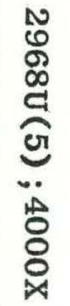

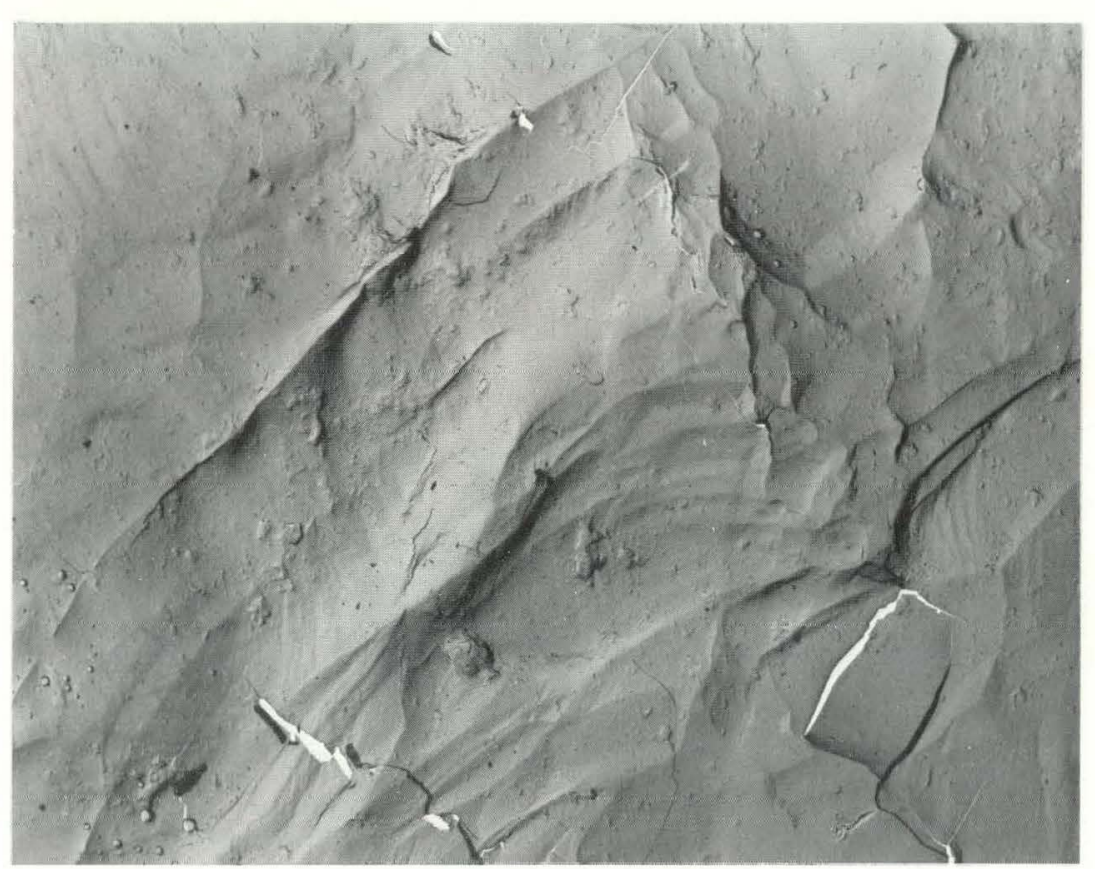

FIGURE 10. Electron Fractographs of Niobium-4 wt $\%$ Vanadium Tested at $-100 \mathrm{C}, 70 \%$ Reduction in Area. KS-59995 Unclassified 
THIS PAGE

WAS INTENTIONALLY

LEFT BLANK 


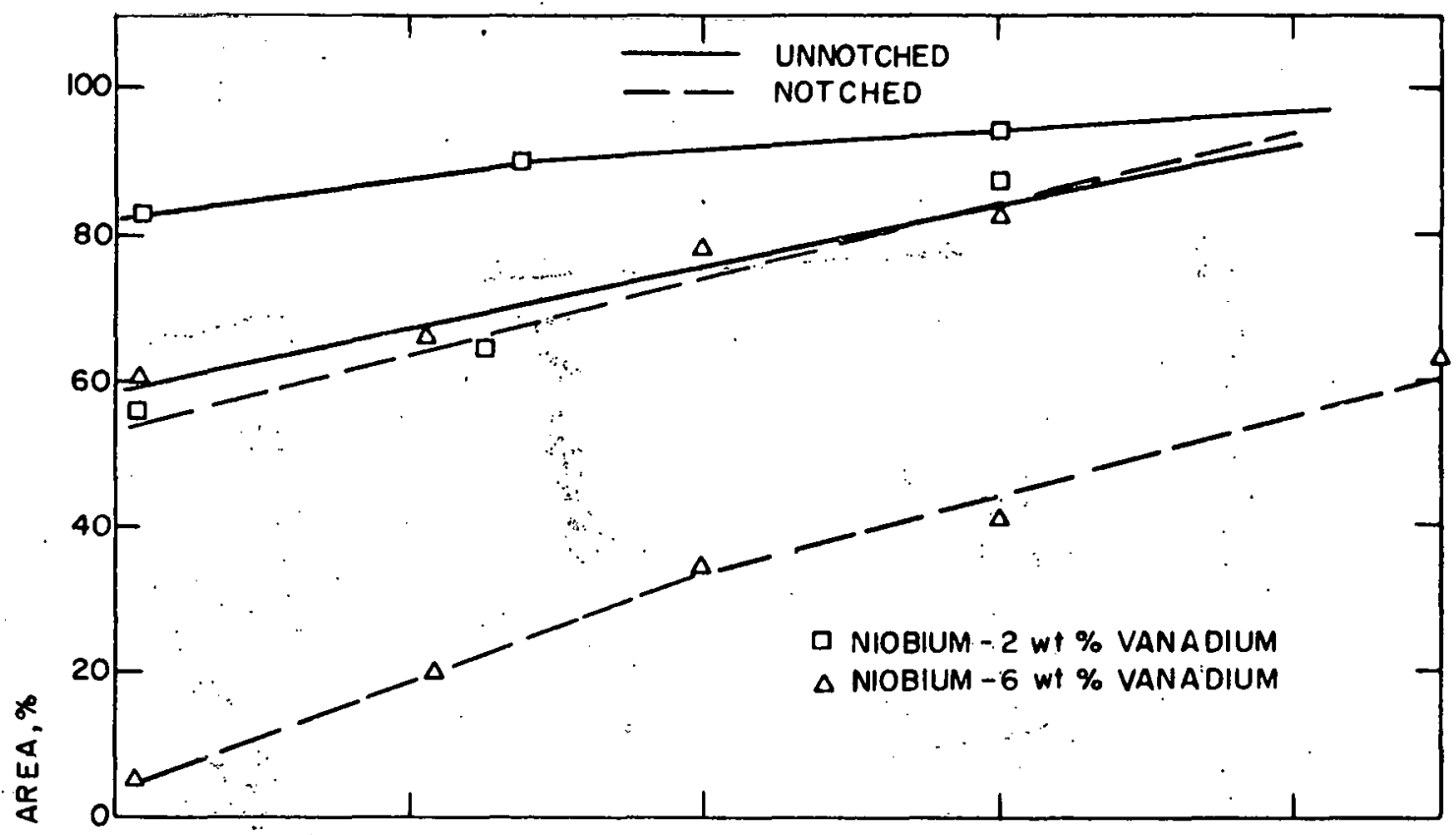

A. Niobium-2 and -6 wt $\%$ Vanadium

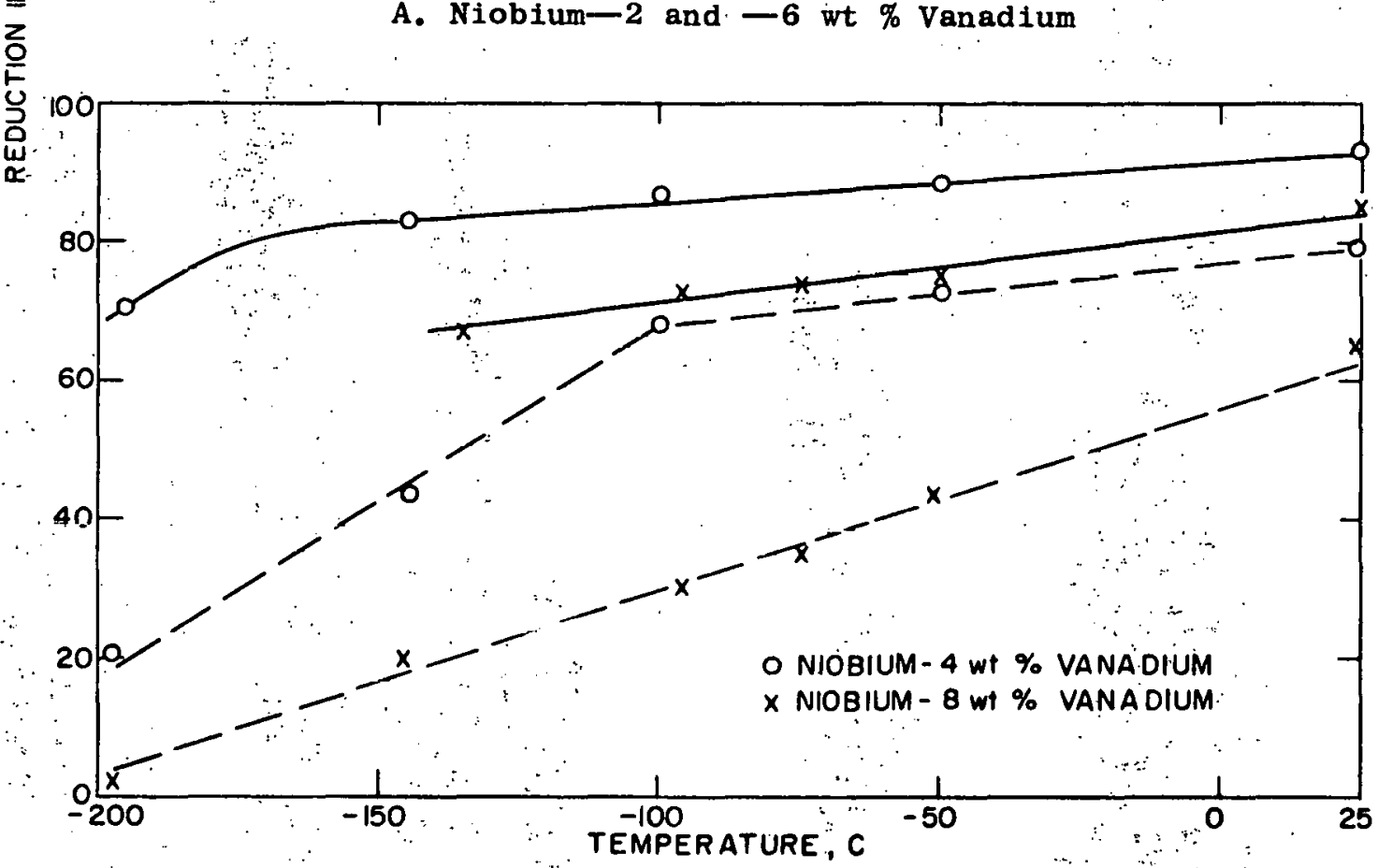

B. Niobium -4 and -8 wt $\%$ Vanadium

FIGURE ll. Effect of Notches on Ductile-to-Brittle

KS-59996

Unclassified 


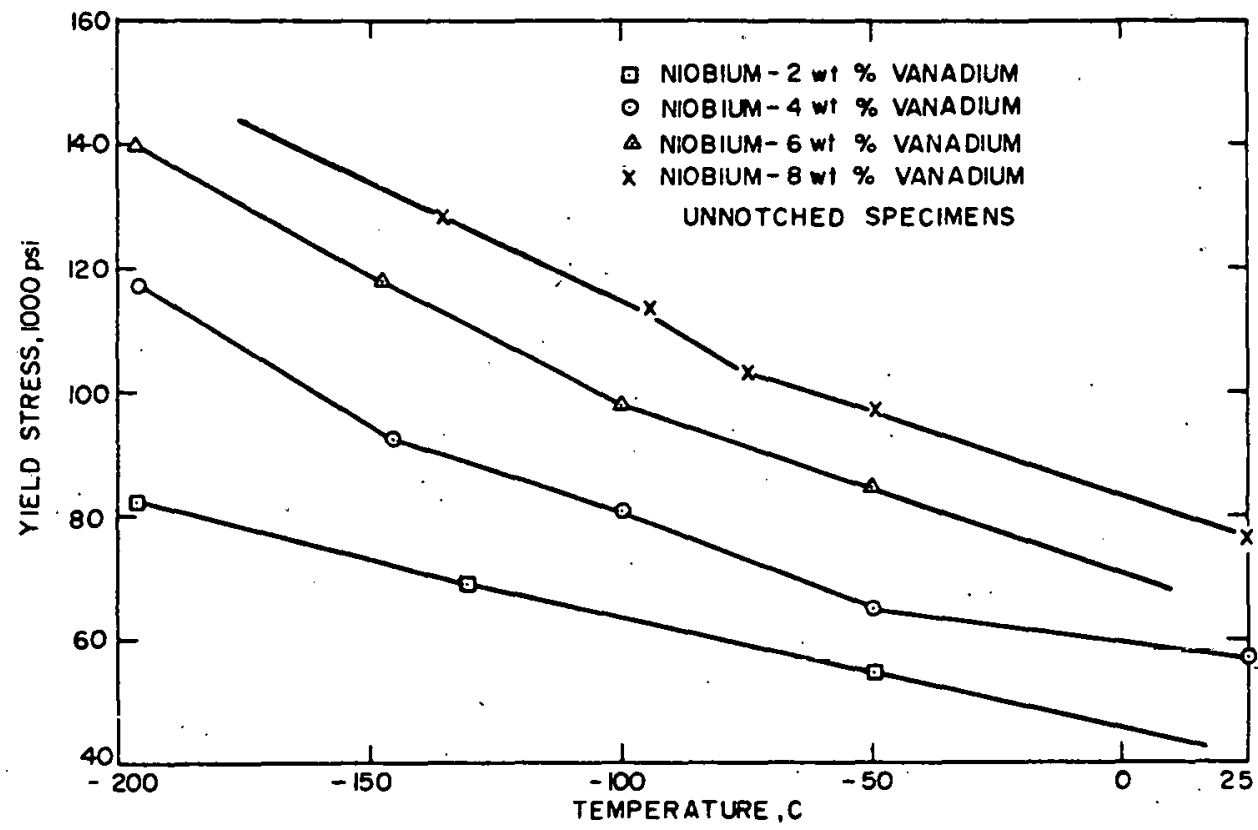

FIGURE 12. Variation of Low-Temperature Yield Stress of Niobium-Vanadium Alloys as a Function of Vanadium and Temperature.

KS-59997

Unclassified

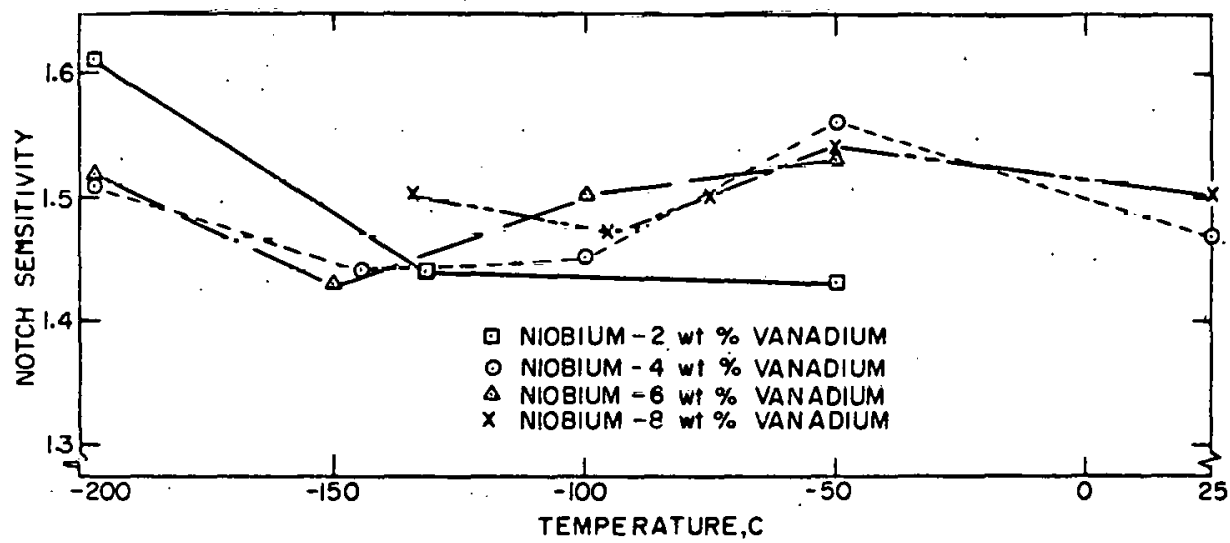

FIGURE 13. Notch Sensitivity of Niobium-Vanadium

Alloys in Temperature Range of -200 to $25 \mathrm{C}$.

$\mathrm{KS}=\mathbf{5 9 9 9 8}$

Unclassified 


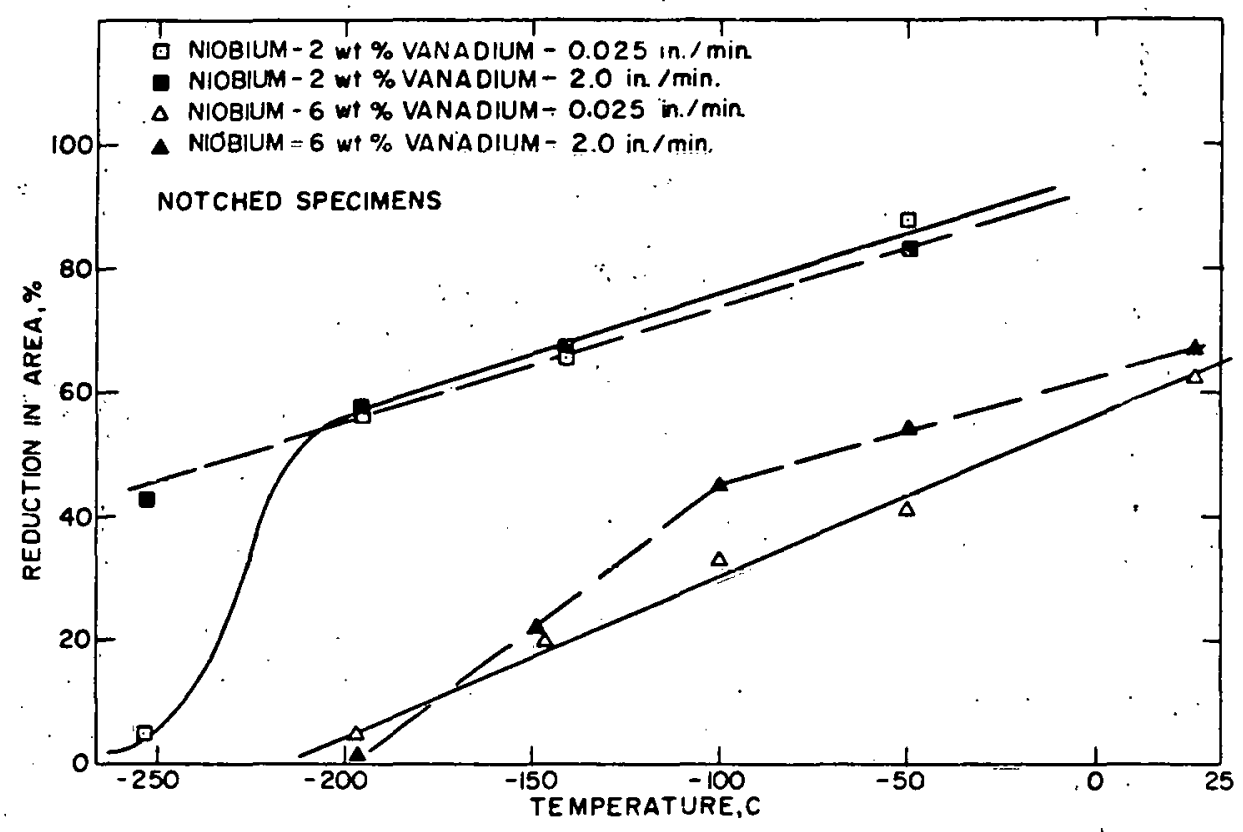

FIGURE 14. Effect of Strain Rate on Ductile-to-Brittle Transition Temperature of Niobium -2 and -6 wt $\%$. Vanadium.

KS-59999

Unclassified

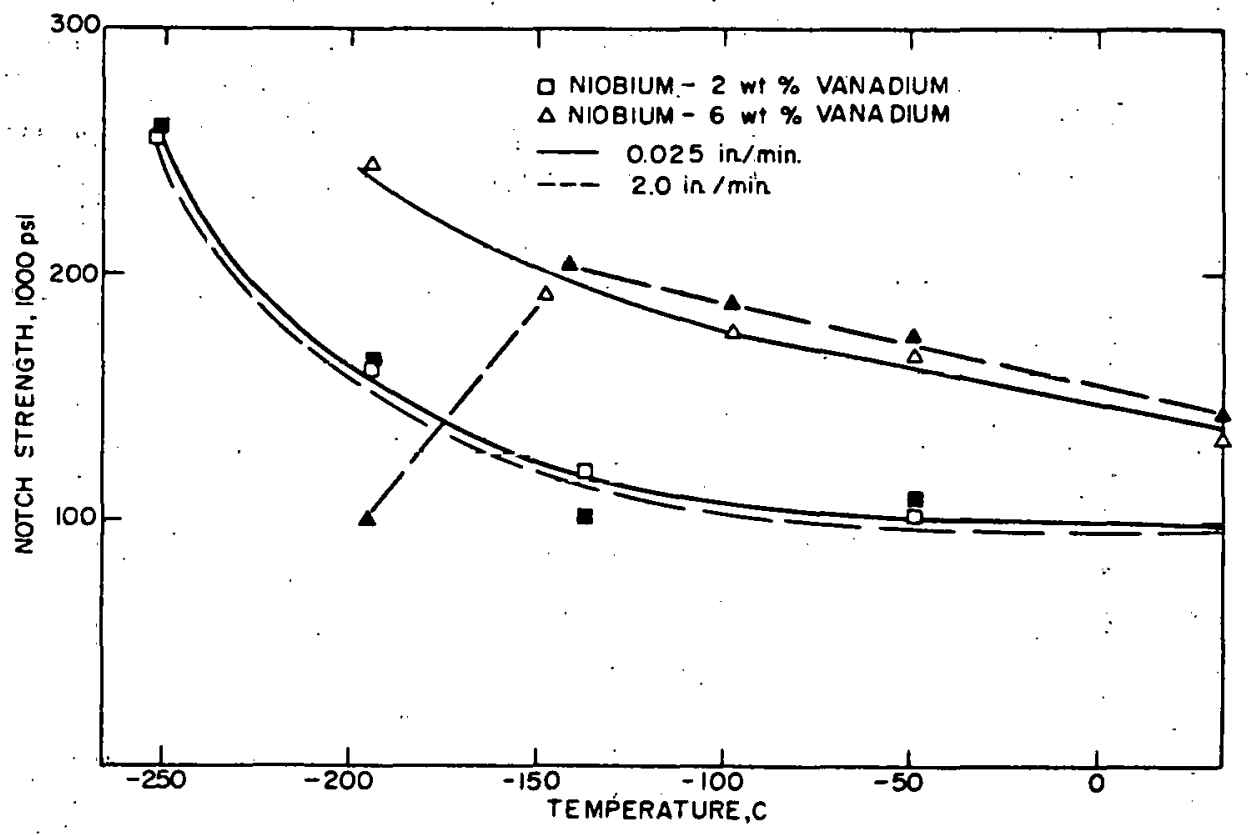

FIGURE 15. Effect of Strain Rate on Low-Temperature Notch Strength of Niobium-2 and $-6 \mathrm{wt} \%$ Vanadium. -KS- 62000 Unclassified 


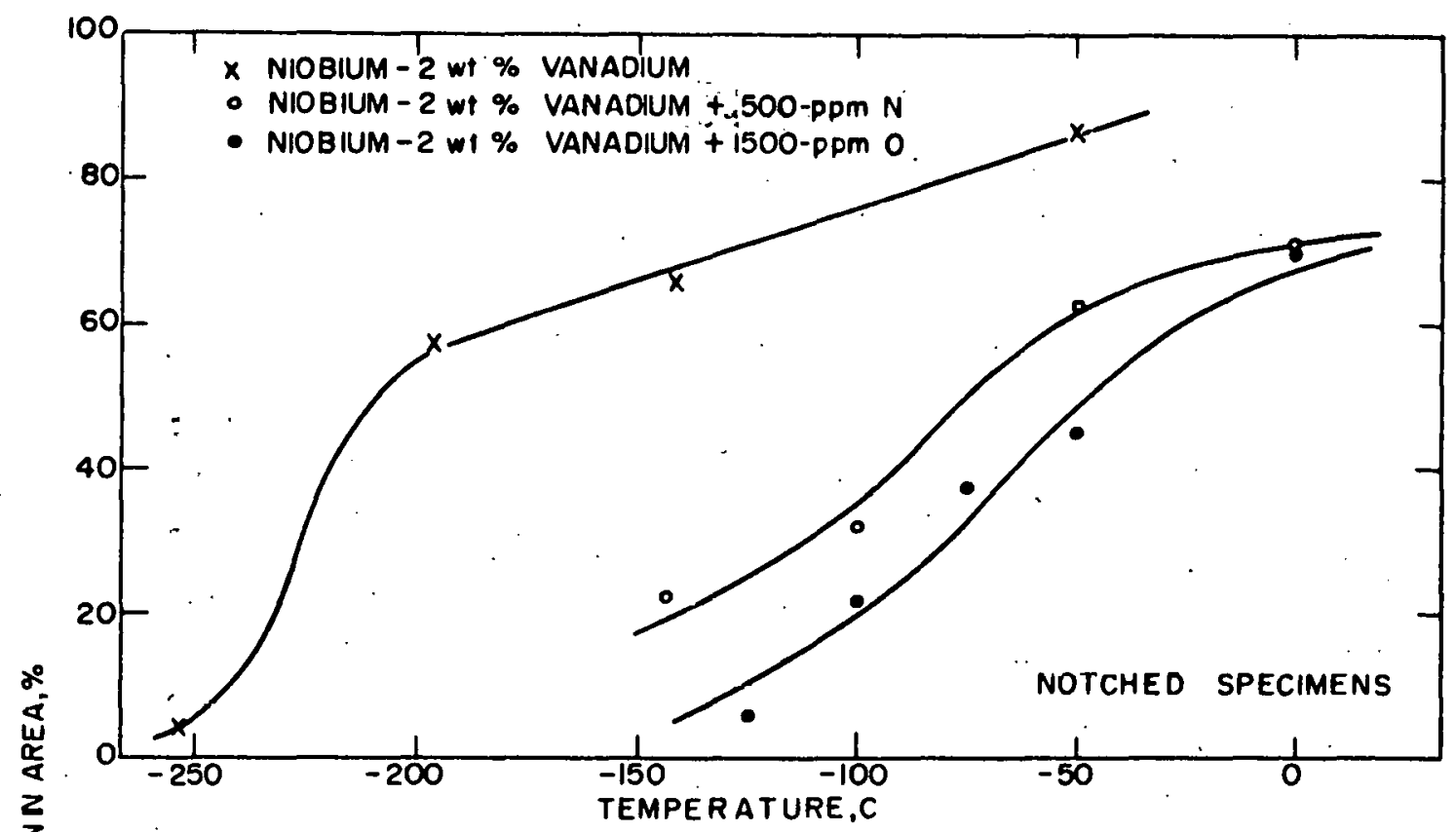

A. Niobium -2 wt \% Vanadium

品

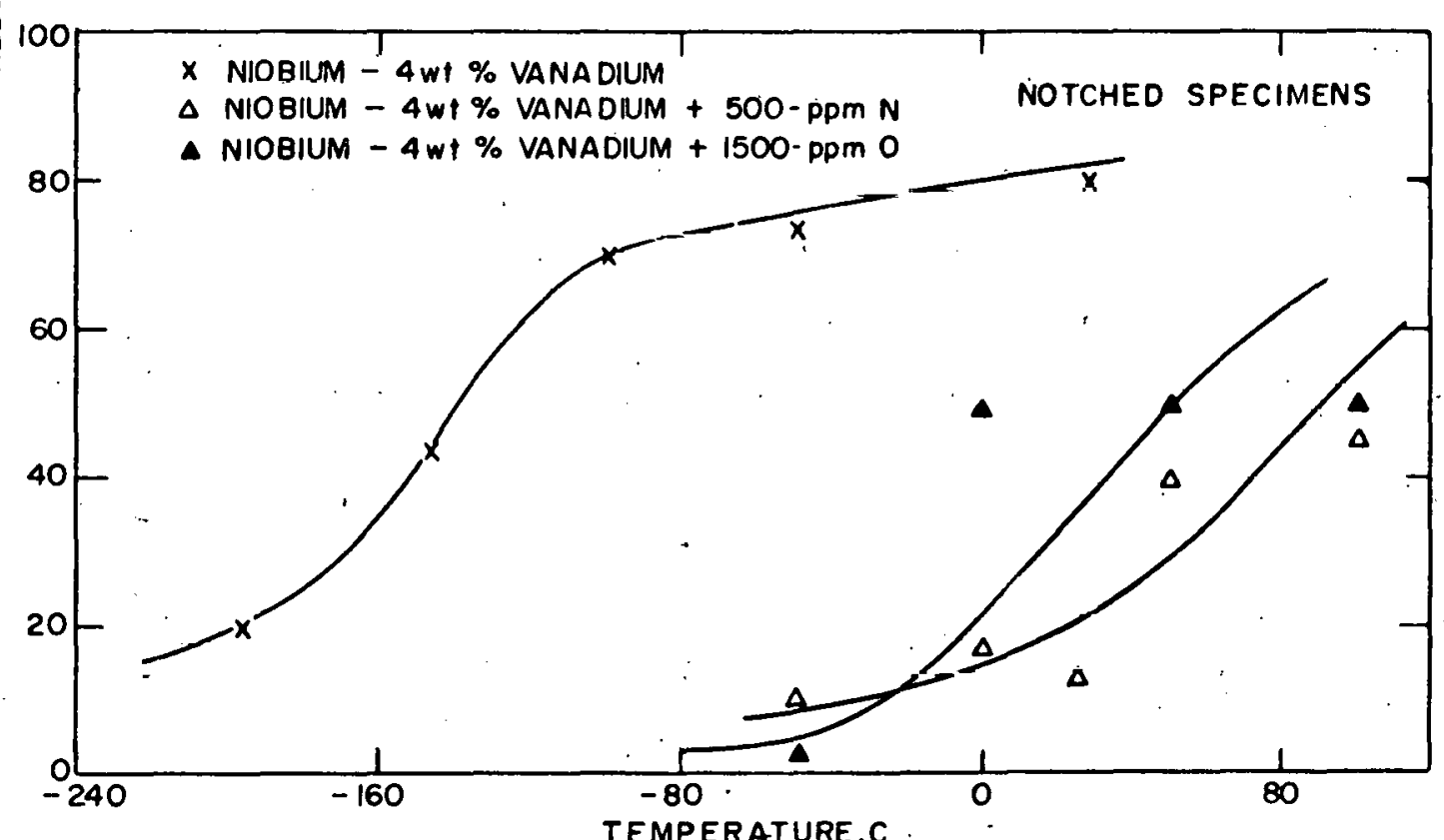

B. Niobium-4 wt \% Vanadium

FIGURE 16. Effect of Nitrogen and Oxygen on Ductile-to-Brittle Transition Temperature.

KS-62001

Unclassified 


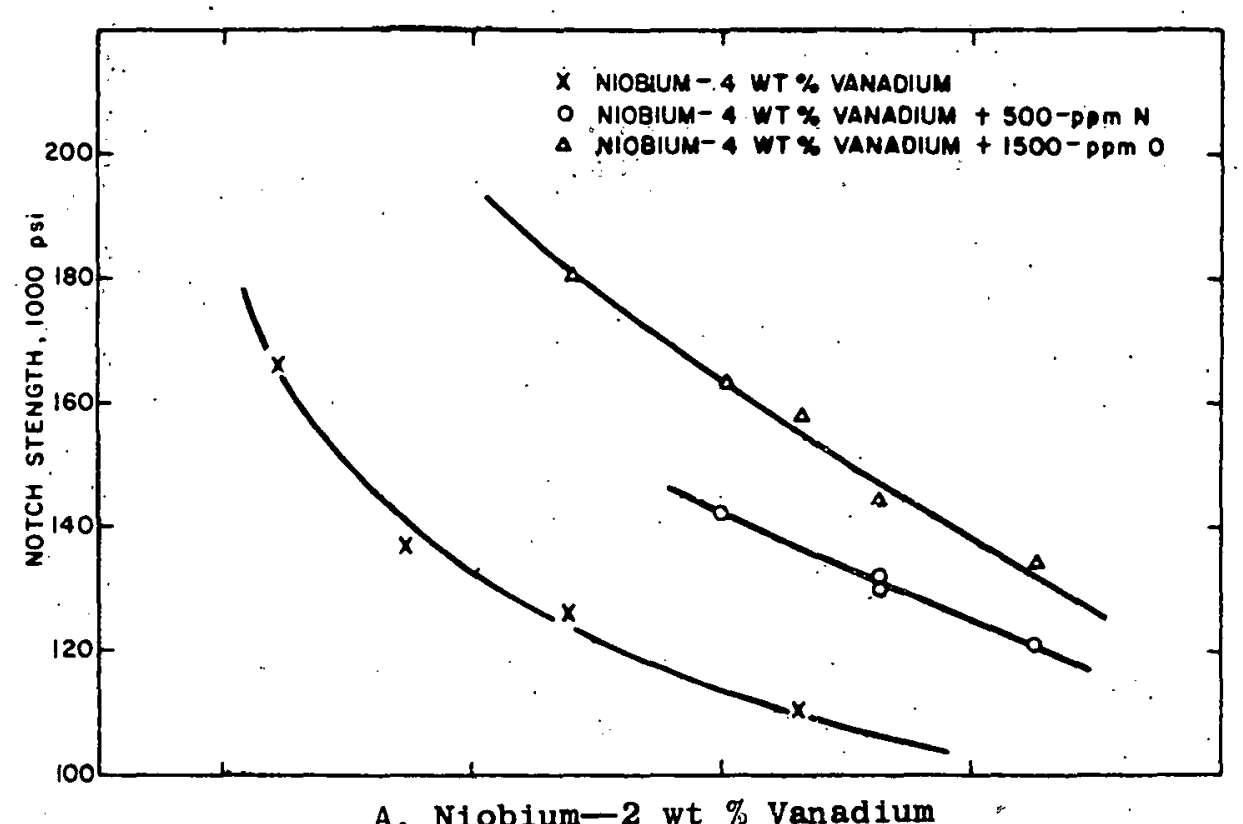

Temperature Range: -160 to $25 \mathrm{C}$.

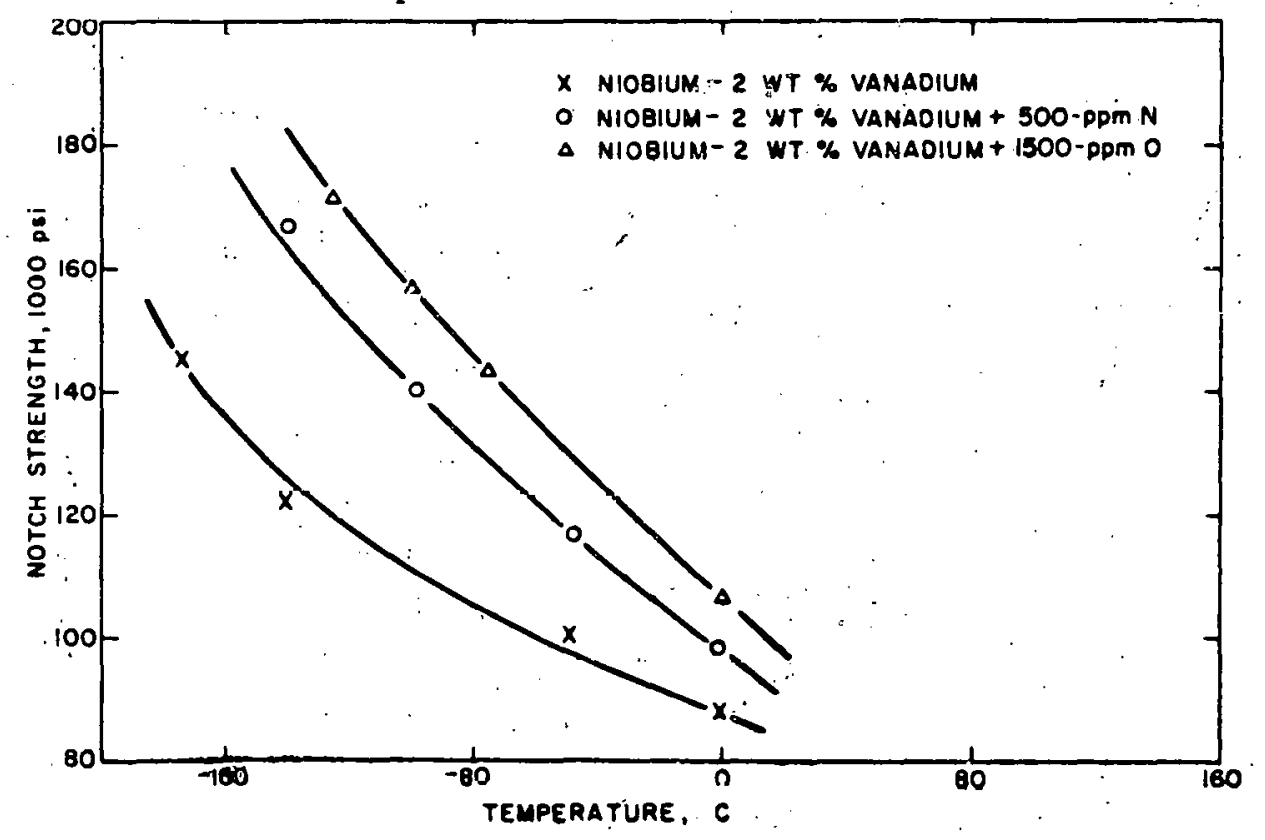

B. Niobium-4 wt $\%$ Vanadiun

Temperature Range: -80 to $100 \mathrm{C}$.

FIGURE 17. Effect of Nitrogen or Oxygen on

$\therefore$ Notch Strength.

KS-62002 .. ; ; Unclassified 
TABLE 3. EFFECT OF NITROGEN AND OXYGEN ON THE TRANSITION TEMPERATURE OF NIOBIUM-VANADIUM AS A FUNCTION OF VANADIUM

\begin{tabular}{|c|c|c|c|c|}
\hline Metal & Interstitial & $\mathrm{ppm}^{*}$ & $\begin{array}{l}{ }^{\circ} \mathrm{C} \text { Increase in } \\
\text { Transition Temp. }\end{array}$ & $\begin{array}{c}\text { ppm to } \\
\text { Increase } 1^{\circ} \mathrm{C}\end{array}$ \\
\hline $\mathrm{Nb}$ & Nitrogen & - & - & - \\
\hline $\mathrm{Nb}^{* *}$ & Oxygen & 1320 & 105 & 12.6 \\
\hline $\mathrm{Nb}-2 \mathrm{~V}$ & Nitrogen & 390 & 123 & 3.2 \\
\hline $\mathrm{Nb}-2 \mathrm{~V}$ & Oxygen & 1100 & 153 & 7.2 \\
\hline $\mathrm{Nb}-4 \mathrm{~V}$ & Nitrogen & 340 & 185 & 1.8 \\
\hline $\mathrm{Nb}-4 \mathrm{~V}$ & Oxygen & 1230 & 225 & 5.5 \\
\hline
\end{tabular}

*It has been estimated that $\sim 300-p p m$ nitrogen and $\sim 1000-p p m$ oxygen are retained in solid solution. ${ }^{7}$

**After Imgram. *

metals or alloys, the transition temperatures are raised; the degree to which they are raised is a function of the interstitial. When the substitutional content is increased, its effect may be to either raise or lower the transition temperature. When the percentage of substitutional atoms is increased in a metal with a bcc crystal structure, the magnitude of variation in transition temperature is a function of the solute.

Begley and Bechtold have studied the effect of near-neighbor alloying elements on the mechanical properties of niobium. 5 Low-temperature studies by these investigators revealed that when compared at equal atom percentages the tungsten-molybdenum group exerted the greatest increase in fracture transition temperature, titanium and hafnium had relatively little effect, and zirconium was intermediate in effect. They contemplated that the effects of vanadium would be similar to those of zirconium.

Other studies by Bartlett, et al., 8 revealed that tungsten and molybdenum additions exhibited identical quantitative effects, increasing the transition temperature by about 30 to $50 \mathrm{~F}$ for each atomic-percent of tungsten or molybdenum added. Tantalum additions to niobium were found to decrease the ductile-to-brittle transition temperature. ${ }^{8}$. Through a correlation of high-temperature strengthening and the effect on the ductile-tobrittle transition temperature for tungsten, molybdenum, and tantalum, they reasoned that additions of vanadium to niobium would raise the ductile-tobrittle transition temperature. 8 
Platte ${ }^{\theta}$ has investigated the effects of titanium, molybdenum, tungsten, vanadium, hafnium, and zirconium additions on the weldability of niobiumbased alloys. In this study, the effect of these additions on the ductileto-brittle transition temperature was determined by bend tests. As the vanadium content of the alloy was increased, the ductile-to-brittle transition temperature was found to rise. The stress at the proportional limit, for a given temperature, was also increased.

In the present investigation, the ductile-to-brittle transition temperature of niobium-vanadium alloys (as determined by tensile-testing of notched specimens) was a linear function of vanadium up to 6 wt. \%. The transition temperature was increased $30 \mathrm{C}$ per weight percent of vanadium. Increasing the vanadium content from 6 to $8 \mathrm{wt}$. \% resulted in an increase of $12 \mathrm{C}$ per weight-percent vanadium addition. The temperature range in which the alloy changes from ductile to brittle behavior increases with vanadium content. This characteristic of a metal - $i_{0} e_{0}$, of having a more abrupt transition with increasing purity - is a common phenomenon; an example is the addition of carbon to iron. ${ }^{10}$

The variation of notch strength, as a function of temperature, incicated that the alloy was not tested in its subtransition range. The notch strength increased with decreasing temperature over the entire temperature range of these tests. Microscopic examination of specimens tested in both the notched and unnotched condition, and at the lowest temperatures, indicated a near absence of mechanical twins. An occasional grain would have two or three twins in an area of concentrated stress, but twinning does not appear to be as predominant in niobium-vanadium alloys as in niobium.

The photomacrographs in Figure 4 indicate the relative amounts of plastic deformation prior to failure as a function of temperature. In the niobium -2 and $-4 \mathrm{wt}$. \% vanadium, the ductility - as measured by reduction in area - remained quite high until the transition temperature range was reached; in this range dinetility decreased abruptly. In the niobium-6 and $-8 \mathrm{wt}$. \% vanadium, the ductility decreased rather linearly with temperature.

The microstructure of specimens sectioned longitudinally was studied rather extensively at low magnifications ( 50 to $75 \mathrm{X}$ ). With this study as a background, selected specimens were studied at 250X. From these studies of the microstructure, the mode of deformation was established. At the root of the notch, initial deformation continued until the stress concentration increased and the specimen failed by transgranular cleavage. This cleavage is shown in the photomicrographs in Figure 8 where cracks are seen to propagate transgranularly.

Electron fractographs were taken of the fracture surface of specimens encompassing the temperature range investigated. The fractographs in Figure $9(A, B$, and C) are of niobium-6 wt. \% vanadium tested at -196 , 
-100 , and 25C. Although the percent reduction in area increases from $5 \%$ at $-196 \mathrm{C}$ to $64 \%$ at $25 \mathrm{C}$, the predominant mode of failure remained cleavage as evidenced by the "river pattern". At high magnification, transgranularcleavage surfaces usually contain a large number of cleavage steps and a "river pattern" of branching cracks. If the material had failed by inter-. granular fracture, the surfaces would appear much smoother, with a general absence of cleavage steps. The fractographs of a niobium-4 wt. \% vanadium specimen tested at $-100 \mathrm{C}$ (Figure 10) revealed that, although the alloy failed by cleavage, the preponderance of the river pattern and cleavage steps was much less than that of the fractographs of niobium-6 wt. \% vanadium tested at the same temperature (Figure 9B): Figure 9B also shows that the intensity of the typical river pattern has diminished compared with that of the test at $-196 \mathrm{C}$ (Figure 9A). Thus, with decreasing vanadium or increasing temperature, quasi-cleavage tends to prevail as the predominant mode of failure.

Notches

In general, a notch affects the mechanical properties of a material by enhancing its tendency for brittle fracture. When a notched specimen is loaded in tension, the metal in the core of the notch must take all of the load. The result is a central mass of highly stressed metal surrounded by a hoop of unstressed metal. The resistance of the unstressed metal to the deformation of the metal in the core results in radial and circumferential stresses. Such a state of stress raises the value of the longitudinal stress required for yielding and contributes to brittle failure. Also, the presence of a notch will increase the effective strain rate which is normally associated with an increase in the transition temperature.

The magnitude of the change in transition temperature caused by the notches cannot be determined from these results because none of the unnotched specimens underwent a ductile-to-brittle transition. However, the daita indicated that the minimum decrease in the transition temperature would be $100 \mathrm{C}$ for the niobium-6 and $-8 \mathrm{wt}$. \% vanadium and about $50 \mathrm{c}$ for the nfublum -2 and -4 wt. \% vanadium. The effect of notches on the ductility was more drastic in the alloys of greater vanadium content. This is reasonable because the lower the inherent ductility of a material the greater the consequence of a notch. When the alloy is ductile, it can flow and thereby relieve the stress at the hase of the notch.

Because of the stress concentration introduced by a notch, the longitudinal stress for yielding is also increased in the ductile region. Therefore, when the metal is tested in the temperature range at which it still retains ductility, the notch will act as a strengthening factor. As the temperature is lowered, however, thereby increasing the resistance to slip, the stress concentration at the notch root will cause cleavage cracks to develop and propagate at a lower nominal stress than that required for the unnotched specimens.

KAPL-3119 
Empirical relationships have' shown that the notch sensitivity (the ratio of the notched to the unnotched strength) of ductile materials should be $\sim 1$. plus the percent notch depth. If the effect of temperature on notch sensitivity is large, the decrease in the notch/unnotched strength ratio should be large when plotted as a function of temperature. But, if the notch sensitivity is altered by alloy additions, the magnitude of the notch-sensitivity parameter should vary.

The notch sensitivity of the niobium-vanadium alloys studied in this investigation had no large or systematic variation as a function of vanadium and/or temperature. The notch reduced the cross-sectional area 50\%; thus the notch sensitivity should correspond to 1.5 if the alloys were not notch-sensitive. The results from the tensile tests at a cross-head motion of $0.025 \mathrm{in.} / \mathrm{min}$ indicated that these alloys are not notch-sensitive since the notch sensitivity was $\sim 1.5$ for all tests, and the deviations from 1.5 as a function of temperature were not large. It has been found that recrystallized niobium becomes notch-sensitive at -256c.11 Since most of the tests in this investigation were performed down to $-196 \mathrm{C}$, it was reasoned that any effect of vanadium on the notch-sensitivity temperature of niobium would be $<60 \mathrm{C}$ for an addition of up to $8 \mathrm{wt}$. $\%$, vanadium.

Strain Rate

In general, an increase in the strain rate has been found to enhance the tendency for brittle fracture at a given temperature because, as proposed by Dieter, ${ }^{10}$ there is less time for plastic flow to occur near microcracks and to thus relieve the stress concentration. As the temperature is decreased and plastic flow or dislocation motion becomes more difficult, a slower strain rate would be sufficient to cause brittle failure.

In this investigation, notched and unnotched specimens of niobium-2 alfd -6 wt. $\%$ vanadium were tensile-tested at cross-head motions of 0.025 and $2.0 \mathrm{in.}$ min in the temperature range of -196 to $25 \mathrm{C}$. The only real evidence of strain-rate sensitivity was the reduced notched strength of niobium-6 wt. $\%$ vanadium tested at $-196 \mathrm{C}$ with the faster strain rate. Any effect on ductility for the niobium-6 wt. \% vanadium tests at $-196 \mathrm{C}$ would be difficult to detect because the percent reduction in area was $<5 \%$ for both cross-head motions.

The tests of the niobium-2 wt. \% vanadium at $-253 \mathrm{C}$ resulted in increased ductility with the higher strain rate. However, the notched strength remained the same for both cross-head motions. At first, it is rather difficult to understand how an increased strain rate could result in an enhancement in ductility. When a specimen is tested at sufficiently low temperatures, however, a very small amount of plastic deformation can cause local heating of the material, with a resulting avalanche of plastic flow. 12 The elastic energy stored in the specimen when the load' is increasing can be converted into heat, thus facilitating plusilic flow in the 
deforming portion of the specimen. When the rate at which the material is: being strained is increased, either by an increase in the cross-head motion and/or by the presence of a notch, there is not sufficient time for the local heat to transfer from the specimen to the refrigerant. Thus, the test becomes adiabatic rather than isothermal. The effective temperature is increased and the material behaves as if tested at a higher temperature. The presence of a notch causes the local heating to be concentrated at the notch root, and the faster strain rate decreases the dissipation time for this heat. Therefore, the anomalous behavior of the niobium-2 wt. $\%$ vanadium tested at $-253 \mathrm{C}$ is not thought to be a result of strain rate, per se, but rather a result of the test's not being isothermal.

Prior studies of the strain-rate sensitivity of niobium indicated no effect of strain rate. ${ }^{13}$ Both notched and unnotched specimens were tested at $-196 \mathrm{C}$ at cross-head motions from 0.005 to $1.0 \mathrm{in.} / \mathrm{min}$ without any significant effect on the tensile properties of the material. Tensile data of notch specimens of niobium-2 and $-6 \mathrm{wt}$. \% vanadium in the temperature range of 325 to $650 \mathrm{C}$ revealed that these alloys were insensitive to a $100-$ fold increase in strain rate. ${ }^{14}$ The experimental data from a variety of tensile tests indicated that niobium and niobium-vanadium alloys containing up to $6 \mathrm{wt}$. \% vanadium were insensitive to strain rate. Therefore, it would not be anticipated that strain-rate sensitivity as a function of vanadium would be a major consideration in selecting the optimum vanadium composition.

Interstitials

A common phenomenon with the transition metals, such as niobium, is a strong dependence of mechanical properties on interstitial impurities. The brittle behavior of metals in Group V-B, such as niobium, is enhanced because the interstitials are in solid solution where they inhibit dislocation motion and reduce the resistance to crack propagation. ${ }^{7}$ In a niobiumbase alloy where the addition of an alloying element, such as vanadium, decreases the lattice parameter, it would be expected that the influence of the interstitial atoms on the mechanical properties would be magnified.

It has been shown ${ }^{15}$ that 500- and 1000-ppm oxygen raised the ductileto-brittle transition temperature in niobium from $-234 \mathrm{C}$ to -196 and $-146 \mathrm{C}$, respectively. Previous investigations ${ }^{16}$ of the effect of interstitials on the mechanical properties of niobium have indicated that nitrogen affects the ductility more drastically than does oxygen.

In the present investigation, the transition temperature of the niobium-2 wt. \% vanadium was increased from about $-225 \mathrm{C}$ to -100 and $-20 \mathrm{C}$ with the addition of 390-ppm nitrogen and 1100-ppm oxygen, respectively. The niobium-2 wt. \% vanadium alloy had a base concentration of 63-ppm nitrogen and 175-ppm oxygen. The addition of 340-ppm nitrogen and 1230-ppm 
oxygen to niobium-4 wt. \% vanadium increased the transition temperature from $-160 \mathrm{C}$ to 25 and $65 \mathrm{C}$, respectively. The base concentration of interstitials in this alloy was 60-ppm nitrogen and 155-ppm oxygen.

Table 3 tabulates the ppm of nitrogen and oxygen required to increase the transition temperature 1C. The data were obtained from notch tensile tests and are representative only of the indicated interstitial concentrations. The concentrations of nitrogen and oxygen likely to be maintained in solid solution in niobium after moderate cooling rates are 300 and 1000 ppm, respectively. ${ }^{7}$ From Table 3 it is seen that nitrogen has a more potent effect on the ductile-to-brittle transition temperature in niobium-vanadium than does oxygen. Also, the decrease in ductility was greater in the alloys of higher vanadium content.

The notch strength of the niobium-2 wt. $\%$ vanadium was increased from 105,000 psi to 130,000 and 145,000 psi by the addition of 390-ppm nitrogen and 1100-ppm oxygen, respectively. In the niobium-4 w.t. \% vanadium alloy, the notch strength was increased from $115,000 \mathrm{psi}$ to 145,000 and 165,000 psi by the addition of 340-ppm nitrogen and 1230-ppm oxygen, respectively. These data indicated again that nitrogen had a greater strengthening effect. Also, either nitrogen or oxygen increased the notch strength, and the magnitude of the increase was greater in the alloys of higher vanadium content.

CONCLUSIONS

The primary conclusions to be drawn from this investigation are:

1. In the notch tensile test, the ductile-to-brittle transition temperature of niobium-vanadium was increased $\sim 30 \mathrm{C}$ per weight-percent addition of vanadium in the range of 2 to 6 wt. \% vanadium, and 120 per weight-percent vanadium in the range of 6 to $8 \mathrm{wt}$. $\%$. If these data are applicable to the irradiated condition, a linear relationship will exist between the postirradiated ductility and the vanadium in the range of 2 to 6 wt. \% vanadium.

2. The unnotched tensile specimens did not exhibit a ductile-tobrittle transition in the temperature range of -196 to $25 \mathrm{C}$. The decrease in ductility due to notches was proportionately greater in the alloys of higher vanadium content. The niobium-vanadium alloys of the compositions studied in this investigation $(2,4,6$, and $8 \mathrm{wt}$. \% vanadium) did not exhibit notch sensitivity in the temperature range investigated (-196 to 25C).

3. The mechanical properties (ductility and tensile stress) were insensitive to strain rate in the temperature ranges of -196 to $25 \mathrm{C}$ for the $2 \mathrm{wt}$. \% vanadium and -150 to $25 \mathrm{C}$ for the 
6 wt. \% vanadium. The notch strength of the niobium-6 wt. \% vanadium was decreased by the increased strain rate at $-196 \mathrm{C}$.

4. The ductile-to-brittle transition temperatures were increased markedly by the addition of nitrogen and oxygen interstitials.

5. Nitrogen affected the ductile-to-brittle transition tempperature in niobium-vanadium alloys more drastically than did oxygen.

6. The magnitude of the effect of interstitials on the mechanical properties of niobium-vanadium increased with increasing vanadium content.

7. The results of the metallographic study indicated that niobium-vanadium was not sensitive to intergranular cracking; rather, most of the cracks propagated transgranularly.

8. The electron fractographs indicated that the predominant mode of failure in niobium-vanadium alloys of the composi-. tions investigated was that of cleavage. 
REFERENCES

1. Maykuth, . . J., et al., Columbiam Metallurgy. New York: Interscience Publisher's, $P_{0} 223$ (1960)。

2. Fisch, H. $A_{0}$, et al., Columbium Metallurgy. New York: Interscience Publishers, P. 597 (1960):

3. Douglass, D. Lo, Nucl。 Sci。 and Eng。, 9:391 (1961)。

4. Private communication. FoW. Kunz.

5: Begley, R. To, and J. H. Bechtold, Jo Less-Common Metals, 3:1 (1961).

6. Kunz, F。 $W_{0}$, and F。 K. Blechinger. Private communication.

7. Hahn, G. T. . et al. Private communication.

8. Bartlett, E. S., et al., Trans。AIME, 227:459 (1963)。

9. Platte, W. N., Welding Research Supplement, P.69, February 1963.

10. Dieter, G. E., Mechanical Metallurgy. New York: McGraw-Hill Book Co., Inc. (1961)。

11. Imgram, A. Go, et al., "Notch Sensitivity of Refractory Metals," Technical Report No. ASK-TR-61-474, January 1962.

12. Basinski; Z. S., Acta Met。, 5:763. (1957)。

13. Imgram, A. Go, et al., "Notch Sensitivity of Refractory Metals," WADD Technical Report 60-778, September 1960.

14. Calhoun, C. D. Private communication.

15. Guy, A. G.; Elements of Physical Metallurgy. Cambridge, Massachusetts: Addison-Wesley Publishing Co., Inc. (1959)。

16. Chalmers, B. Physical Metallurgy. New York: John Wiley \& Sons, Inc. (1959). 
THIS PAGE

\section{WAS INTENTIONALLY \\ LEFT BLANK}


APPENDIX A. CHEMICAL ANAIYSIS OF . THE MATERIAL (AS-SWAGED) below:

The general chemical analysis of the ingots is presented in the table Ingot Number

\begin{tabular}{|c|c|c|c|c|c|}
\hline & $A-210$ & $A-216$ & $A-218$ & $A-219$ & $A-220$ \\
\hline 0 & 175 & 195 & 155 & 265 & 360 \\
\hline $\mathrm{N}$ & 63 & 106 & 81 & 126 & 139. \\
\hline $\mathrm{H}$ & 26 & 4 & 20 & 24 & 16. \\
\hline$C$ & 85 & $<15$. & 65 & 55 & 70 \\
\hline $\mathrm{V}^{*}$ & 1.97 & 2.03 & 4.05 & 6.04 & 7.98 \\
\hline $\mathrm{Fe}$ & $<50$ & 50 & 50 & 50 & 50 \\
\hline Mn & $<10$ & $<10$ & $<10$ & $<10$ & $<10$ \\
\hline $\mathrm{Mg}$ & $<10$ & $<10$ & $<10$ & $<10$ & $<10$ \\
\hline $\mathrm{Cv}$ & $<5$ & $<5$ & $<5$ & $<5$ & $<5$ \\
\hline $\mathrm{Pb}$ & $<20$ & $<20$ & $<20$ & $<20$ & $<20$ \\
\hline$S i$ & 20 & 20 & 50 & 20 & 20 \\
\hline $\mathrm{Co}$ & $<20$ & $<20$ & $<20$ & $<20$ & $<20$ \\
\hline $\mathrm{Sn}$ & $<10$ & $<10$ & $<10$ & $<10$ & $<10$ \\
\hline $\mathrm{Ni}:$ & $<10$ & $<10$ & $<10$ & $<10$ & 20 \\
\hline Mo & $<50$ & $<50$ & $<50$ & 125 & 75 \\
\hline Al & 50 & $:<50$ & $<50$ & $<50$ & $<50$ \\
\hline B & $<5$ & $<5$ & $<5$ & $<5$ & $<5$ \\
\hline
\end{tabular}

*Weight percent。

Note: Impurities reported in ppm by weight.

A number of chemical analyses were performed at various stages in this investigation. The vanadium was analyzed by wet chemistry, oxygen by the Leco inert argon fission method, hydrogen by hot extraction, nitrogen by Kjeldahl distillation, and the impurities by emission spectroscopy. 